\title{
The Multisensor Advanced Climatology of Liquid Water Path (MAC-LWP)
}

\author{
Gregory S. Elsaesser, ${ }^{\mathrm{a}, \mathrm{b}}$ CHRistopher W. O’Dell ${ }^{\mathrm{c}}$ MATTHEW D. Lebsock, ${ }^{\mathrm{d}}$ RAlF BenNARTZ, \\ THOMAS J. GREENWALD, ${ }^{\mathrm{f}}$ AND FRANK J. WENTZ ${ }^{\mathrm{g}}$ \\ a Department of Applied Physics and Applied Mathematics, Columbia University, New York, New York \\ ${ }^{\mathrm{b}}$ NASA Goddard Institute for Space Studies, New York, New York \\ ${ }^{\mathrm{c}}$ Department of Atmospheric Science, Colorado State University, Fort Collins, Colorado \\ ${ }^{\mathrm{d}}$ Jet Propulsion Laboratory, California Institute of Technology, Pasadena, California \\ ${ }^{\mathrm{e}}$ Department of Earth and Environmental Sciences, Vanderbilt University, Nashville, Tennessee \\ ${ }^{\mathrm{f}}$ Cooperative Institute for Meteorological Satellite Studies, University of Wisconsin-Madison, Madison, Wisconsin \\ ${ }^{\mathrm{g}}$ Remote Sensing Systems, Santa Rosa, California
}

(Manuscript received 21 December 2016, in final form 11 September 2017)

\begin{abstract}
The Multisensor Advanced Climatology of Liquid Water Path (MAC-LWP), an updated and enhanced version of the University of Wisconsin (UWisc) cloud liquid water path (CLWP) climatology, currently provides 29 years (1988-2016) of monthly gridded $\left(1^{\circ}\right)$ oceanic CLWP information constructed using Remote Sensing Systems (RSS) intercalibrated $0.25^{\circ}$-resolution retrievals. Satellite sources include SSM/I, TMI, AMSR-E, WindSat, SSMIS, AMSR-2, and GMI. To mitigate spurious CLWP trends, the climatology is corrected for drifting satellite overpass times by simultaneously solving for the monthly average CLWP and the monthly mean diurnal cycle. In addition to a longer record and six additional satellite products, major enhancements relative to the UWisc climatology include updating the input to version 7 RSS retrievals, correcting for a CLWP bias (based on matchups to clear-sky MODIS scenes), and constructing a total (cloud + rain) liquid water path (TLWP) record for use in analyses of columnar liquid water in raining clouds. Because the microwave emission signal from cloud water is similar to that of precipitation-sized hydrometeors, greater uncertainty in the CLWP record is expected in regions of substantial precipitation. Therefore, the TLWP field can also be used as a quality-control screen, where uncertainty increases as the ratio of CLWP to TLWP decreases. For regions where confidence in CLWP is highest (i.e., CLWP:TLWP > 0.8), systematic differences in MAC CLWP relative to UWisc CLWP range from $-15 \%$ (e.g., global oceanic stratocumulus decks) to $+5 \%-10 \%$ (e.g., portions of the higher latitudes, storm tracks, and shallower convection regions straddling the ITCZ). The dataset is currently hosted at the Goddard Earth Sciences Data and Information Services Center.
\end{abstract}

\section{Introduction}

Quantifying regional variations in cloud liquid water path $\left(\mathrm{CLWP}^{1}\right)$ can be important for understanding and diagnosing cloud-climate feedbacks (e.g., Stephens 2005; Zelinka et al. 2012a,b). However, the extent to which CLWP is useful for understanding radiative feedbacks depends on the vertical thickness and density of the cloud structures themselves. For instance, although CLWP-rich deep convective clouds (10-15 km thick)

\footnotetext{
${ }^{1}$ CLWP as defined in this study and product is the nonprecipitating, suspended liquid water mass in an atmospheric column.
}

Corresponding author: Gregory S. Elsaesser, gregory.elsaesser@ columbia.edu effectively decrease the amount of longwave radiation that escapes to space, they also reflect substantial incoming solar radiation. Therefore, the overall impact of such clouds on radiative forcing is more minimal, and the utility of CLWP for diagnosing radiative feedbacks is not clear. Conversely, warm, low clouds are similar to deep clouds in terms of solar albedo (e.g., Klein and Hartmann 1993), but they differ in that their emitted longwave radiation signature is comparable to that of Earth's surface. The net impact may be a cooling (warming) of the surface as these cloud fields increase (decrease) in coverage. Therefore, at least in terms of liquid clouds, understanding and quantifying CLWP variations for low-cloud regimes may be more impactful for increasing our understanding of cloud-climate feedbacks (Boucher et al. 2013).

These different radiative impacts of liquid-containing clouds have led many to conclude that low-cloud feedbacks 
are among the largest sources of uncertainty in determining future climate projections (Bony and Dufresne 2005; Soden and Held 2006; IPCC 2007). In fact, the range in climate responses among a number of global climate models (GCMs) can often be tied to the simulation of low-cloud fields (Bony and Dufresne 2005). To this end, improved physical parameterizations for simulating lowcloud fields are an important goal of the upcoming phase 6 of the Coupled Model Intercomparison Project (CMIP6; Eyring et al. 2016). Coincident with model development, GCM representations of low-cloud fields must be gauged against a CLWP climate data record (CDR) that exhibits minimized regional cloud biases, provides a reasonable estimate of regional uncertainty, and is of sufficient length (the latter, of course, being satellite-record limited). Furthermore, clouds evolve on subdaily time scales, and physical processes to be captured in GCM parameterizations occur on hourly time scales. GCM-simulated clouds can begin to be evaluated at the process level if CLWP at monthly time scales is supplemented by diurnal cycle information.

We address these observational goals with the construction and maintenance of the Multisensor Advanced Climatology of Liquid Water Path (MAC-LWP). Wellevaluated microwave retrieval products from Remote Sensing Systems (RSS) serve as the input CLWP files for the construction of the climatology. Because of the use of low-frequency microwave radiation in CLWP retrieval algorithms, microwave CLWP products are less sensitive to overlying ice clouds (Liu and Curry 1993; Bennartz and Bauer 2003) and are available at all hours of the day, thus minimizing diurnal cycle artifacts that would arise as result of daytime sampling only [e.g., visible (VIS)/near-infrared (IR) products] (Lebsock and Su 2014). In defining MAC-LWP, liquid water path (LWP) includes both the CLWP and total (cloud + rain) liquid water path (TLWP) components. With regard to CLWP, the MAC-LWP product is an extension and enhancement of the University of Wisconsin (UWisc) CLWP climatology (available from 1988 to 2009) introduced in O'Dell et al. (2008, hereafter OWB08). We refer readers to OWB08 for additional extensive discussion on systematic errors in CLWP retrievals and a comparison of UWisc CLWP climatology to prior CLWP climatologies. The inclusion of TLWP is new to the MAC-LWP dataset, and it should prove useful in the evaluation of climate models as they begin to include prognostic precipitation.

We outline our methodology for aggregating individual satellite products and discuss the relevant components of the algorithm used to simultaneously determine both the monthly mean CLWP/TLWP and CLWP diurnal cycle parameters (available as a function of month, averaged over all years) in section 2. The gridded data fields made available are also discussed. We discuss improvements relative to the UWisc product: namely, our approach for correcting a CLWP bias that was revealed in microwave-VIS/IR analyses in clear-sky scenes and the construction of the TLWP field that can be used as a quality-control screen for confidence in the monthly CLWP estimates. We present broad results regarding the climatology of CLWP along with comparisons to the UWisc product in section 3, highlight potential climate research applications using the new product in section 4 , and discuss future plans in section 5 .

\section{Construction of the MAC-LWP record}

MAC-LWP seamlessly combines all $0.25^{\circ}$-resolution CLWP retrieval products produced from the latest version of Remote Sensing Systems' ocean-only retrieval algorithm (Wentz 2013). These version 7 RSS data replace the version 6 data used in the latest-updated UWisc climatology. Gridded data are available for both ascending and descending satellite overpasses, and are described in detail online (at www.remss.com). The contributing satellite sensors and record lengths, along with the equatorial overpass times for the sun-synchronous sensors, are shown in Fig. 1. CLWP is retrieved using a multistep regression algorithm (Wentz and Meissner 2000, 2007) that is incorporated into the Unified Microwave Ocean Retrieval Algorithm (UMORA; Hilburn and Wentz 2008). The algorithm has undergone much development over the past 15 years, with details available in the following series of papers (among others): Wentz (1997), Wentz and Spencer (1998), Wentz and Meissner (2000), and Hilburn and Wentz (2008). Detailed satellite intercalibration has been performed to ensure that no spurious jumps in the data record result from the changing sensor availability through time. The latest-version 7-calibration methodology is detailed in Wentz (2013). As of this writing, collectively, all products span the period 1988-2016, thus affording a 29-yr climatology of ocean-only CLWP. In addition to CLWP, we also use the RSS $0.25^{\circ}$ surface rainfall $(R)$, column-integrated water vapor (WVP), and surface wind (WIND), as explained in the following two sections.

\section{a. Correction of a CLWP bias in microwave retrieval products}

Several sources of systematic error exist in passive microwave estimates of CLWP. Partitioning the emission signal between cloud and rainwater is most likely the largest source of error (Lebsock and Su 2014). This error derives from the cloud/rain mass partitioning, the 

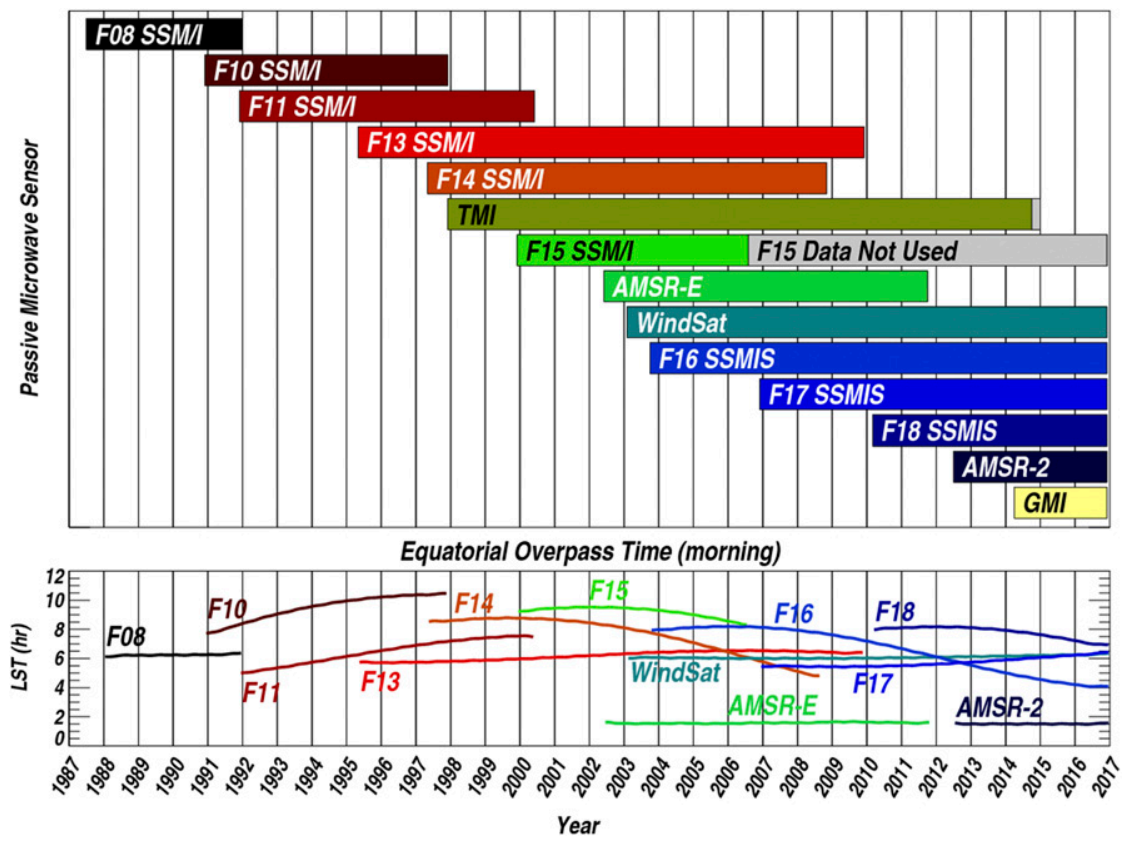

FIG. 1. (top) Satellite sensors contributing to the MAC-LWP climate data record [Special Sensor Microwave Imager/Sounder (SSMIS)]. Gray portions of the TMI and F15 bars denote periods not used due to quality-control concerns. (bottom) Morning equatorial overpass times (LSTs) for all utilized sun-synchronous sensors as a function of year.

assumptions of the precipitation drop size distribution, and the vertical structure of the cloud and precipitation water. Systematic errors are also associated with inhomogeneity within the sensor field of view (Bremen et al. 2002), cloud emission temperature (OWB08), instrument calibration, and uncertainty in the surface emissivity and spectroscopy (Meissner and Wentz 2012). These biases, particularly those associated with rain and cloud structure, are difficult to quantify and correct given the lack of an independent verification dataset for CLWP, but they may be as large as a factor of 2 in regions of shallow cumulus convection (Lebsock and $\mathrm{Su}$ 2014).

In this section we address one aspect of the bias that can be readily quantified that is most likely related to instrument calibration and/or bias in the radiative transfer: the CLWP clear-sky bias. Studies have found that RSS passive microwave CLWP tends to be (on average) nonzero in cases where coincident Moderate Resolution Imaging Spectroradiometer (MODIS; Platnick et al. 2003) observations show cloud-free scenes (e.g., Greenwald et al. 2007; Greenwald 2009; Lebsock and $\mathrm{Su}$ 2014). It is possible that WVP or WIND or both are biased, with the residual microwave emission signal being artificially attributed to CLWP (i.e., a cross-talk issue). However, WVP and WIND have been found to be unbiased against in situ data (e.g., Mears et al. 2001; Meissner et al. 2001; Trenberth et al. 2005; Wentz 2015).
Such results argue against widespread cross-talk issues; although, in the less-commonly observed higher WVP or WIND scenes, where smaller magnitude WVP and WIND biases may be less apparent and studied, such issues may still be prevalent. Biases in the emissivity and/or atmospheric gaseous (oxygen, water vapor, etc.) absorption models used in the retrieval algorithm may be responsible for the CLWP biases. Either way, while one cannot definitively state the source of CLWP biases, bias correction is an important goal of the MAC-LWP product.

Using the MODIS Collection 6 Level 2 (i.e., $1 \mathrm{~km}$ ) cloud mask and the version 7 Level 2B (i.e., pixel level) AMSR-E CLWP, we follow the approach of Greenwald et al. (2007) and Greenwald (2009) to determine the extent to which clear-sky biases exist in the latest RSS passive microwave CLWP products. Cloud-free AMSRE pixels are identified from the MYD35_L2 daytime cloud mask (thus, theoretically, CLWP $=0$ ). Only AMSR-E pixels that are-in their entirety-determined to be probably or confidently clear are retained in the analysis. It is possible that nearby AMSR-E pixels containing precipitation could impact the clear-sky pixels; however, it was found these cases rarely occur. This clear-sky CLWP from the AMSR-E L2B product (2008 only) was composited as a function of AMSR-E WVP and WIND. Instead of finding that CLWP $=0$ everywhere, it was found that CLWP systematically varied 
TABLE 1. Coefficients for the clear-sky bias correction [Eq. (1)].

\begin{tabular}{cc}
\hline \hline Coefficients & \multicolumn{1}{c}{ Value } \\
\hline$p_{00}$ & 0.006107 \\
$p_{10}$ & -0.0001258 \\
$p_{01}$ & -0.002365 \\
$p_{20}$ & $-1.393 \times 10^{-5}$ \\
$p_{11}$ & $9.531 \times 10^{-5}$ \\
$p_{02}$ & 0.000208 \\
$p_{30}$ & $3.127 \times 10^{-7}$ \\
$p_{21}$ & $-7.838 \times 10^{-7}$ \\
$p_{12}$ & $-4.802 \times 10^{-6}$ \\
$p_{03}$ & $-8.658 \times 10^{-6}$ \\
\hline
\end{tabular}

as a function of WVP and WIND. Because satellite sensors are intercalibrated (Wentz 2013), it is expected that this is not unique to AMSR-E and that the bias is characteristic of all microwave sensors used in the MAC-LWP product.

A WVP- and WIND-dependent bias correction was developed for the $0.25^{\circ}$-resolution RSS input based on the abovementioned empirical analysis. First, a cubic surface was fit to the observed clear-sky biases in order to extrapolate the observations to unobserved portions of the WVP/WIND space, given by the following equation:

$$
\begin{aligned}
\mathrm{CLWP} \_\mathrm{clr}= & p_{00}+p_{10} \mathrm{WVP}+p_{01} U+p_{20} \mathrm{WVP}^{2} \\
& +p_{11} U \mathrm{WVP}+p_{02} U^{2}+p_{30} \mathrm{WVP}^{3} \\
& +p_{21} U \mathrm{WVP}^{2}+p_{12} \mathrm{WVP}^{2}+p_{03} U^{3},
\end{aligned}
$$

where $U=$ WIND $\left(\mathrm{m} \mathrm{s}^{-1}\right)$, CLWP_clr $\left(\mathrm{kg} \mathrm{m}^{-2}\right)$ is the CLWP in clear skies (derived, again, using AMSR-E), and WVP has units of $\mathrm{kg} \mathrm{m}^{-2}$. The fitting coefficients for Eq. (1) are provided in Table 1. The extrapolation is only weakly constrained by observations and is likely unreliable at the edges of the WVP/WIND domain, so it is capped at $\pm 30 \mathrm{~g} \mathrm{~m}^{-2}$. We note that these regimes occur rarely in the data and that bias correction in these regimes contributes negligibly to the CLWP data record. Figure 2 shows the WVP/WIND-dependent CLWP bias. For all oceanic scenes, this CLWP bias is subtracted from each satellite record (at the native $0.25^{\circ}$ RSS resolution) as a function of WVP and WIND prior to ingestion into the MAC-LWP merging algorithm. We make two assumptions in applying the clear-sky bias correction. First, we assume that the clear-sky bias does not systematically vary with the presence of clouds nor immediately delta drop to zero when cloud fraction becomes nonzero. The implication of this assumption is that the bias identified in clear sky can be corrected in all pixels (including cloudy-sky pixels). Evidence suggests this may be a reasonable assumption, since biases between AMSR-E and MODIS CLWP for warm clouds exhibit a similar behavior to the clear-sky biases for the same categories of WVP and WIND (Greenwald 2009). Second, we assume that the bias is constant for all utilized microwave sensors, which is likely realistic as a result of the similarity in microwave sensors used in RSS product creation (i.e., passive microwave imaging channels at similar frequencies), the intercalibration that has been applied to the observed brightness temperatures by RSS, and the use of an identical retrieval algorithm on each sensor.

The global mean bias correction is $1.14 \mathrm{~g} \mathrm{~m}^{-2}$, although regional differences are larger. This global mean correction is a factor of $\sim 6$ smaller than that found in Lebsock and Su (2014) for the version 6 RSS AMSR-E product $\left(6.3 \mathrm{~g} \mathrm{~m}^{-2}\right)$. The decrease in the bias is likely due to the inclusion of negative CLWPs in the RSS version 7 product, which were previously forced to zero (Hilburn et al. 2010). The bottom panels of Fig. 2 show the regional pattern of the mean bias correction for boreal winter and summer. The overall effect is to decrease CLWP in the western Pacific (WPAC) and ITCZ regions (consistent with the finding that the CLWP is positively biased in high-WVP regions), and to increase CLWP for higher-latitude regions (lower WVP and higher WIND speeds, where the CLWP is largely negatively biased in the top panel of Fig. 2). Smaller increases occur in stratocumulus decks. Additionally, we find that the impact on CLWP trends was minimal.

Since the empirical bias correction was derived during year 2008 at the AMSR-E pixel level, we evaluate the effect of the correction on $1^{\circ}$-gridded CLWP in clear-sky MODIS scenes during years 2009 and 2010. We use the daily Level 3 MODIS $1^{\circ}$-gridded product (MYD08_D3 collection; Platnick et al. 2015) and proceed by storing the grid center latitude, longitude, and time for all daytime- and ocean-only overpass segments where the $1^{\circ}$ cloud fraction is zero. The total number of $1^{\circ}$ clear-sky counts is shown in the top-right panel of Fig. 3. With respect to processing the microwave products, as we read the RSS daytime AMSR-E $0.25^{\circ} \mathrm{CLWP}$ estimates using the MAC algorithm and compute the $1^{\circ}$ average, for grid centers collocated in space and time with the MODIS clear-sky box, we record the CLWP estimate and, at the end, average them over the entire 2009-10 period. We repeat this aggregation for two additional experiments: for the first, we apply our clear-sky bias correction equation to the input CLWP data prior to averaging (as discussed earlier); for the second, we apply both the clear-sky bias correction and the diurnal cycle correction (the latter correction being derived and discussed in section 2c). For all experiments, we do not 

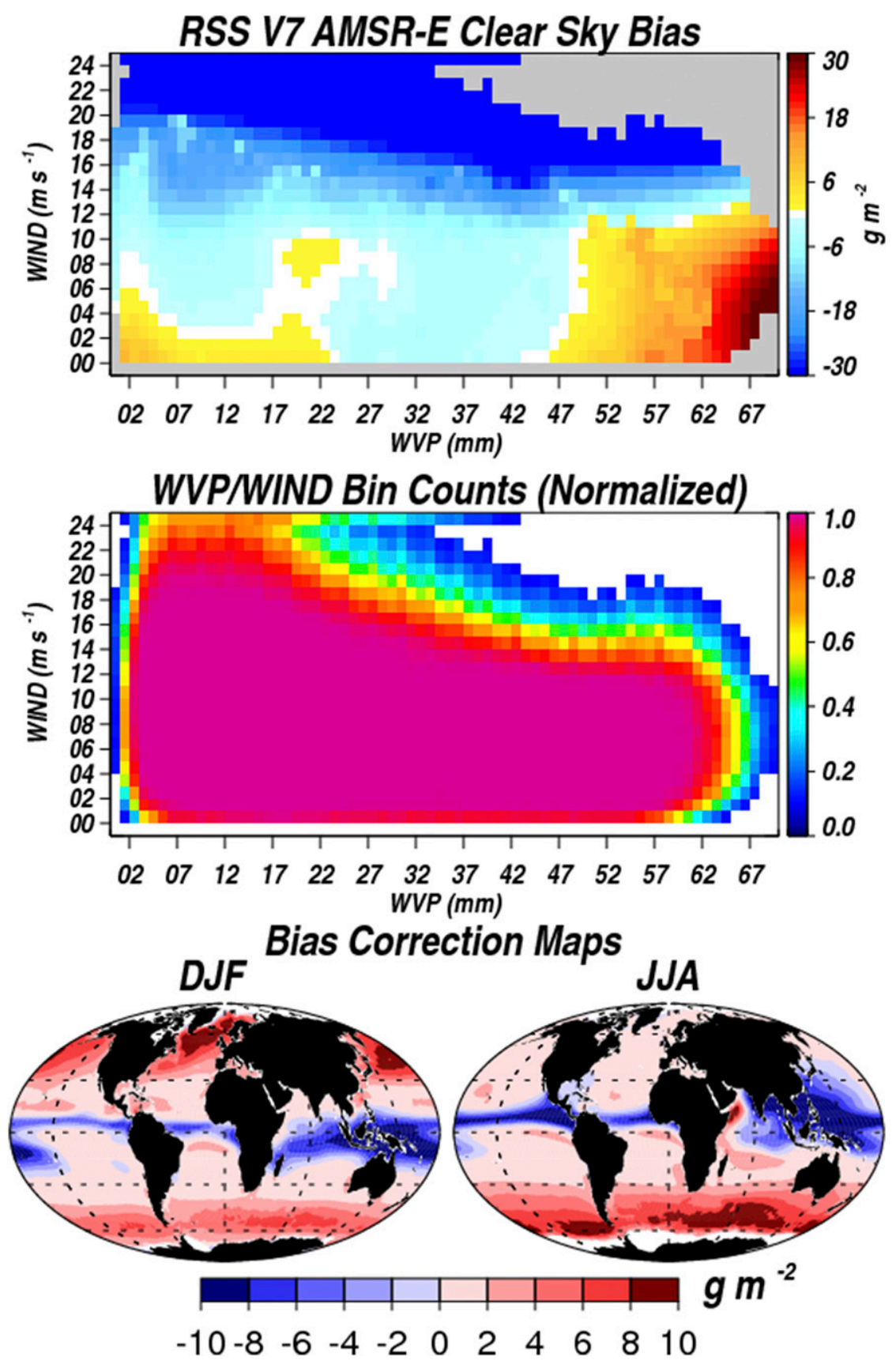

FIG. 2. (top) RSS) version 7 AMSR-E CLWP biases as a function of WVP and WIND for clear scenes identified from MODIS data. (center) Histogram of WVP and WIND computed by summing all RSS WVP and WIND counts for each sensor dataset used in the MAC-LWP product (each bin is normalized by the maximum count over all bins). (bottom) For DJF and JJA, MAC CLWP minus CLWP from a test product constructed (using the MAC algorithm) without the WVP- and WIND-dependent bias correction applied to each input sensor dataset.

tally AMSR-E/MODIS data for the first and last $3 \mathrm{~h}$ of each day because of how daily averages are computed (such that parts of orbits at the beginning/end of subsequent/prior days are overwritten, and thus the daily average may include data from a different day). These orbital seams are found over the Pacific Ocean. This is the reason that large portions of the Pacific Ocean are masked out for analysis, as evident in Fig. 3. 

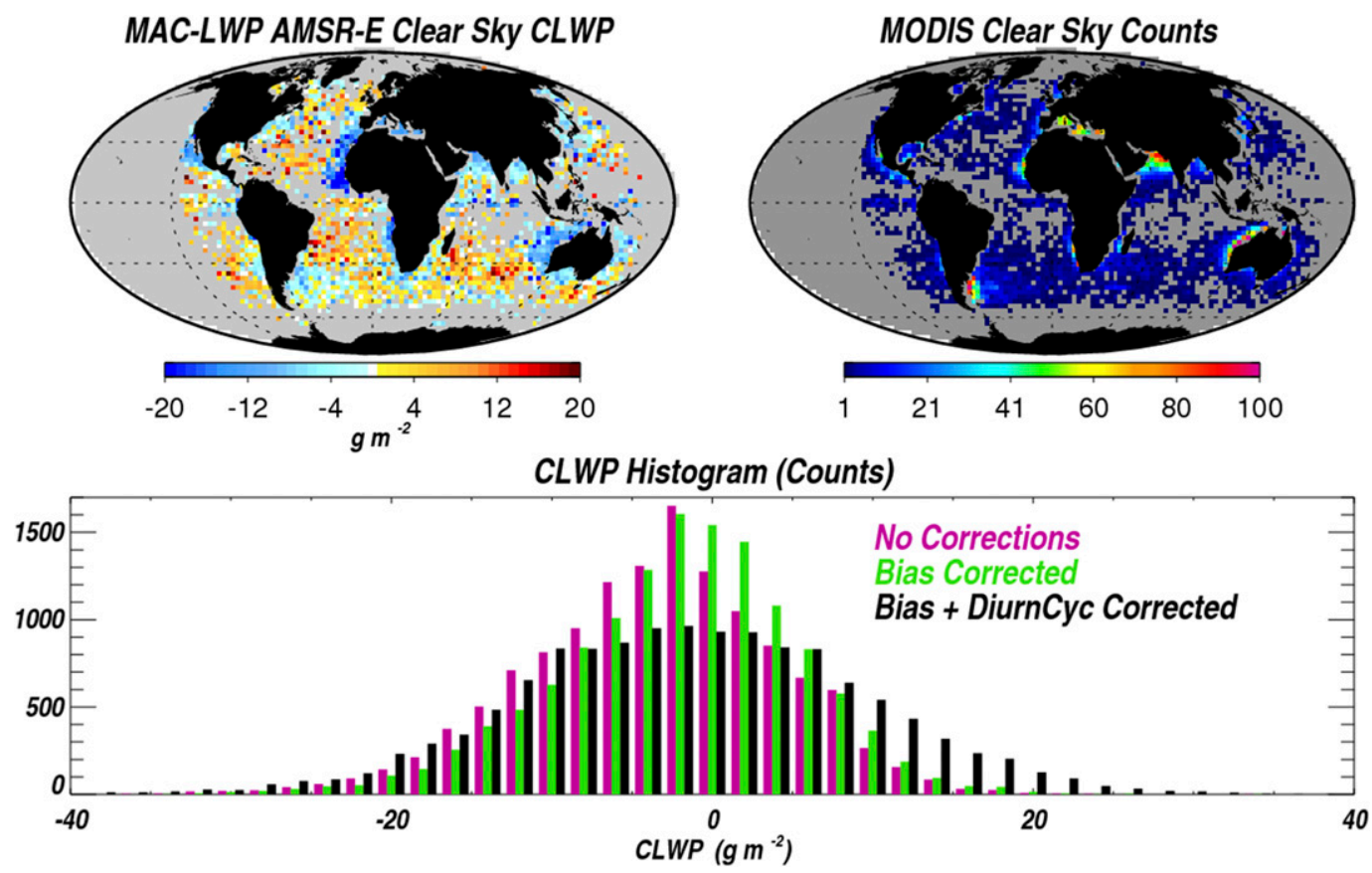

FIG. 3. (top left) Global map of $1^{\circ}$ bias-corrected AMSR-E CLWP calculated as the average of all CLWP observed during times when the MODIS (MYD08_D3, $1^{\circ}$ grids, daytime only) product indicates $100 \%$ clear sky. (top right) Corresponding MODIS $1^{\circ}$ clear-sky counts. (bottom) Global histograms of the $1^{\circ}$-gridded AMSR-E CLWP without the clear-sky bias correction, with the bias correction, and with both the bias and diurnal cycle corrections applied.

Histograms of the $1^{\circ}$-gridded CLWP estimates for these three experiments are shown in Fig. 3. In theory, CLWP is $0 \mathrm{~g} \mathrm{~m}^{-2}$. Without the bias correction ("No Corrections"), the histogram is skewed to the left with a mean (median) CLWP bias of $-2.37(-1.88) \mathrm{g} \mathrm{m}^{-2}$. With the clear-sky bias correction ("Bias Corrected"), the histogram becomes less skewed and centered closer to zero, and the calculated global mean (median) bias improves to $-0.95(-0.42) \mathrm{g} \mathrm{m}^{-2}$. When we include both the diurnal cycle and clear-sky corrections, the histogram broadens but remains comparably biased relative to the case with the clear-sky correction only (mean/ median is $-0.65 /-0.68 \mathrm{~g} \mathrm{~m}^{-2}$ ). We include the latter experiment because the diurnal cycle correction is included, and thus it represents the closest approximation to the MAC-LWP methodology. Importantly, the overall global bias is not degraded in this case. A spatial map of the AMSR-E CLWP (after the clear-sky correction) is provided in the top-left panel of Fig. 3. Most striking is the residual systematic negative bias off the west coasts of major continents, consistent with the remaining longer tails of the histograms in Fig. 3 extending to negative CLWPs. A number of these locations are close to major deserts, and large dust particles blown off the continents may provide enough scattering to reduce the 37-GHz brightness temperature used in CLWP retrieval [e.g., Ge et al. (2008) discuss such issues for this microwave frequency where depressions of up to $5 \mathrm{~K}$ can occur]. A systematically reduced brightness temperature would lead to a consistently smaller retrieved CLWP. Overall, while clear-sky CLWP is in better agreement with MODIS in the global-average sense, future investigations of regional parameters impacting the retrievals will have to be performed.

\section{b. Computation of individual sensor TLWP fields}

As mentioned, algorithms relying upon passive microwave radiation for cloud water retrieval often have difficulty distinguishing the radiative signal arriving from precipitation-sized hydrometeors (i.e., rainwater) from that of cloud water (Bennartz et al. 2010). Microwave attenuation is strongly related to the TLWP, with some variability arising as a result of dependence on drop size distributions (DSDs) that likely vary with environment. To separate CLWP from TLWP, assumptions must be made about the ratio of cloud to precipitating liquid, the precipitation DSD, droplet fall speeds, and the vertical distribution of the condensate. Reliable observations of such variables are lacking, and thus most retrieval algorithms have historically treated the separation more simply (e.g., Petty 1994; Wentz and Spencer 1998). Below a threshold of $180 \mathrm{~g} \mathrm{~m}^{-2}$, in the RSS retrieval algorithm, all TLWP is assumed to be CLWP (Hilburn and Wentz 2008). Above this threshold, RSS computes 
CLWP through the use of the following equation (Wentz and Spencer 1998; Hilburn and Wentz 2008):

$$
\operatorname{CLWP}=180(1+\sqrt{H R}),
$$

where $H$ is the height of the rain column $(\mathrm{km})$, and $R$ is the surface rainfall rate $\left(\mathrm{mm} \mathrm{h}^{-1}\right)$. Variable $H$ is assumed to be the height of the freezing level and is parameterized as a function of sea surface temperature (SST). The formulations for $H$, provided in Hilburn and Wentz (2008), are based on regressions of freezing-level heights on SSTs from the National Centers for Environmental Prediction (NCEP) reanalysis product.

The form of Eq. (2) itself is likely to not capture the complete physical relationship between $R, H$, and CLWP. But form aside, it is also expected that there will be variability in the threshold for nonzero rainwater content [e.g., Tropical Rainfall Measuring Mission (TRMM) Microwave Imager (TMI) retrievals discussed in Berg et al. (2006) and Elsaesser and Kummerow (2008)]. Cloud-rain processes are complicated, and thus large uncertainty may be introduced into the CLWP climatology for regions where TLWP approaches $180 \mathrm{~g} \mathrm{~m}^{-2}$ (and again, even below this threshold, since conversion of cloud to rainwater is environment dependent). Evidence that some aspect of the RSS cloud-rain partitioning is biased is revealed by the correlation of CloudSat rainwater path with the bias of MODIS and AMSR-E CLWP for low-lying liquid clouds (Lebsock and Su 2014). Given the inherent uncertainty in the cloud-rain partitioning methods, one way to mitigate using biased CLWP in the MAC-LWP climatology is to screen oceanic regions for which TLWP is substantially larger than CLWP. Here, we outline the mathematical steps taken to reproduce the TLWP field to facilitate such filtering of the data.

We use optimally interpolated SSTs (Reynolds et al. 2002) and Eqs. (22a)-(22c) from Hilburn and Wentz (2008) to infer $H$. By using the RSS $R$ and assuming it is constant with height over $H$ [Hilburn and Wentz 2008, Eq. (21)], we can reverse engineer the $0.25^{\circ} \mathrm{CLWP}$ retrieval to compute TLWP for each satellite record. Consistent with the RSS algorithm, we assume a Marshall-Palmer exponential DSD and the following general formulations [also provided and discussed in Bennartz and Petty (2001)]:

$$
\begin{gathered}
N(D)=N_{0} e^{-\lambda D} \\
N_{0}=A R^{B} \\
\lambda=C R^{E},
\end{gathered}
$$

where $N(D)$ is the number of drops per volume and size interval; $N_{0}=8 \times 10^{6} \mathrm{~m}^{-4}, \lambda$ varies with rainfall rate; and $A, B, C$, and $E$ are constants. With a
Marshall-Palmer DSD, $A=N_{0}$ and $B=0$. We can integrate Eq. (3) multiplied by the mass of a drop of diameter $D$ (assuming a liquid water density $\rho_{w}=1000 \mathrm{~kg} \mathrm{~m}^{-3}$ ) to arrive at the following formulation for rainwater content (RWC):

$$
\mathrm{RWC}=\rho_{w} \pi \frac{A R^{B}}{\left(C R^{E}\right)^{4}} .
$$

The RSS algorithm, following Wilheit et al. (1977), assumes $C$ to be $81.6 \mathrm{~mm} \mathrm{~h}^{-1}$. Note that when all parameters are converted to SI units, $C$ becomes $171.3 \mathrm{~m} \mathrm{~s}^{-1}$, which is comparable to the $172.1 \mathrm{~m} \mathrm{~s}^{-1}$ value provided in Table 1 of Bennartz and Petty (2001), and $E$ is fixed at -0.21 . Substituting all constants into (and algebraically rearranging) Eq. (6), recalling the assumed constant RWC with height over $H$, and adding the result to CLWP, we arrive at the following expression for TLWP:

$$
\mathrm{TLWP}=\mathrm{CLWP}+H\left(0.091 R^{0.84}\right),
$$

where for clarity TLWP and CLWP are in $\mathrm{kg} \mathrm{m}^{-3}, H$ is in $\mathrm{km}$, and $R$ in $\mathrm{mm} \mathrm{h}^{-1}$. We then proceed with computing TLWP for each sensor product.

\section{c. Multisensor data record construction and available output fields}

The satellite data merging process largely follows the UWisc approach, and we refer the reader to section 3 of OWB08 for an in-depth discussion. We summarize important points here and note any differences in the methodology used. We also refer the reader to the MAC-LWP algorithm theoretical basis document (Elsaesser et al. 2015) for additional technical details on combining satellite swaths. All $0.25^{\circ} \mathrm{CLWP}$, TLWP, and observation times [local solar times (LSTs)] are binned to a $1^{\circ}$ resolution. Thus, the $1^{\circ}$ grids are gridbox average estimates of all scenes, since all $0.25^{\circ}$ estimates, whether clear sky (theoretically, CLWP $=0$ and TLWP $=0$ ) or not, are included. For the non-sunsynchronous TMI product, OWB08 previously neglected data over the $30^{\circ}-40^{\circ}$ latitude belts because of concerns in how multiple ascending (or descending) overpasses-sensing at different LSTs-were averaged. However, we have determined that the reported LST and CLWP are still the most recent data at the higher TRMM latitudes, and not an average over previous ascending (or descending) swaths. Therefore, diurnal cycle information is retained, and we use these data now in our $1^{\circ}$ averages. The use of the precessing Global Precipitation Measurement (GPM) Microwave Imager (GMI) also allows for greater resolving of the diurnal cycle for latitudes between $40^{\circ}$ and $60^{\circ}$. While 
the amplitude and phases of the diurnal cycles over midlatitude open ocean are likely more random and noncyclical (i.e., variation is more influenced by synoptic-scale weather systems), distinct CLWP diurnal cycles near higher-latitude coasts may be present during some seasons; at this point though, with less than 3 years of GMI data available, we are as yet unable to determine any notable differences in CLWP near coasts compared to the product derived without GMI. For each $1^{\circ}$ grid box and month, we also store the standard deviation of CLWP $\left(\sigma_{\text {CLWP }}\right)$, TLWP $\left(\sigma_{\text {TLWP }}\right)$, and the number of $0.25^{\circ}$ RSS pixels going into each grid box.

Figure 1 shows the suite of satellites (used in the MAC-LWP product) observing Earth at varying equatorial overpass times. On any given day, for sunsynchronous satellites and a diurnal cycle of clouds well approximated by a first harmonic sinusoid, varying observation times have no impact on the computation of the daily average. However, varying overpass times (either from combining different satellites or the same satellite with temporally drifting overpass times) superposed upon a diurnal cycle characterized by higher harmonics implies a potentially spurious variation in retrieved CLWP. This is especially the case for periods where the availability of orbiting sensors is limited (e.g., prior to 1993). The removal of such a diurnal cycle effect prevents artificial trends and variability from being introduced into the CDR arising from a variation in the LST of the observations over time (i.e., Fig. 1), and thus this is one important component of our merging technique. Fortunately, the diurnal cycle problem for orbiting microwave sensors is, overall, less of an issue relative to sensors observing in the VIS/IR spectrum (Waliser and Zhou 1997).

As in OWB08, a harmonic regression method is used to simultaneously compute the fit for both the mean monthly diurnal and semidiurnal (i.e., second harmonic) cycles, and the monthly mean CLWP. The predictor variables are trigonometric functions of LST, and the approach produces monthly means that are automatically corrected for diurnal cycle effects. For each grid box and month, the LWP is modeled using the following sinusoidal function:

$$
\begin{aligned}
\operatorname{CLWP}\left(Y_{i}, \operatorname{LST}_{i}\right)= & \overline{\operatorname{CLWP}}\left(Y_{i}\right)+A_{1} \cos \omega\left(\mathrm{LST}_{i}-T_{1}\right) \\
& +A_{2} \cos 2 \omega\left(\mathrm{LST}_{i}-T_{2}\right)+\varepsilon,
\end{aligned}
$$

where $\operatorname{CLWP}\left(Y_{i}, \operatorname{LST}_{i}\right)$ is the CLWP of sensor measurement $i$ at year $Y$ and time LST. The top panels of Fig. 4 show $\operatorname{CLWP}\left(Y_{i}, \mathrm{LST}_{i}\right)$ for three grid boxes. The $\overline{\operatorname{CLWP}}\left(Y_{i}\right)$ is the best-fit average of CLWP for a given year (e.g., the weighted average of all the same-colored CLWP measurements, taking into account the intramonthly variability in CLWP and sample counts). Term $A_{1}\left(T_{1}\right)$ is the amplitude (phase) of the firstharmonic fit, $A_{2}\left(T_{2}\right)$ is the amplitude (phase) of the second-harmonic fit, $\omega$ is the radial frequency corresponding to a 24 -h period, and $\varepsilon$ is an error term that is considered independent of all mentioned variables. This error term is discussed at length in OWB08 as well. The inclusion of this term allows us to compute statistical errors on the monthly CLWP estimates and the diurnal cycle fit parameters (all of which we make available, as shown in Table 2). The covariance matrix corresponding to the fit parameters can be used in standard error propagation packages to compute the envelope of uncertainty on the diurnal cycle for any grid box and month; example uncertainty envelopes are shown in Fig. 4.

Overall, for any grid box, year, and month, in order for a fit to be derived (whether a weighted-mean or sinusoid fit), the following criteria must be met: 1) a minimum of 10 years of data; 2) for any year, at least 10 (or 3) days had to be sampled by sun- (or nonsun-) synchronous sensors; and 3) the range of days had to exceed 25 (4) for the sun (or nonsun-) synchronous sensors. Such requirements ensure that a given month is well sampled over time (as opposed to days clustered toward the beginning, middle, or end of a given month during any year). No sinusoid fit is performed if a temporal gap of greater than $12 \mathrm{~h}$ occurs without a CLWP $\left(Y_{i} \mathrm{LST}_{i}\right)$ measurement. Additionally, if there is a gap of greater than $5 \mathrm{~h}$ in a given month for which no $\operatorname{CLWP}\left(Y_{i}\right.$, $\mathrm{LST}_{i}$ ) measurements are available, then a fit is performed for only the first harmonic of the diurnal cycle. These gap thresholds follow the general Nyquist sampling frequency thresholds necessary for fitting cycles with periods of 12 and $24 \mathrm{~h}$.

Once we remove the diurnal cycle fit from the CLWP measurements for each grid box and month, the actual intramonthly variability estimates are calculated through use of the standard pooled variance equation that computes the standard deviation of a dataset using only the averages and standard deviations of the subcomponents. Here, the diurnal cycle adjusted $\operatorname{CLWP}\left(Y_{i}, \mathrm{LST}_{i}\right)$ estimates are the averages, and the associated $\sigma_{\text {CLWP }}$ estimates are the subcomponent standard deviations. Each error bar on $\operatorname{CLWP}\left(Y_{i}, \operatorname{LST}_{i}\right)$ in Fig. 4 is actually the $\sigma_{\mathrm{CLWP}} / \sqrt{n}$, where $n$ is the sample count. While the diurnal cycle fitting methodology has been tailored to CLWP, we perform the exact same technique on the TLWP fields. We make available all CLWP parameter fields and error estimates, and all TLWP monthly mean estimates and 

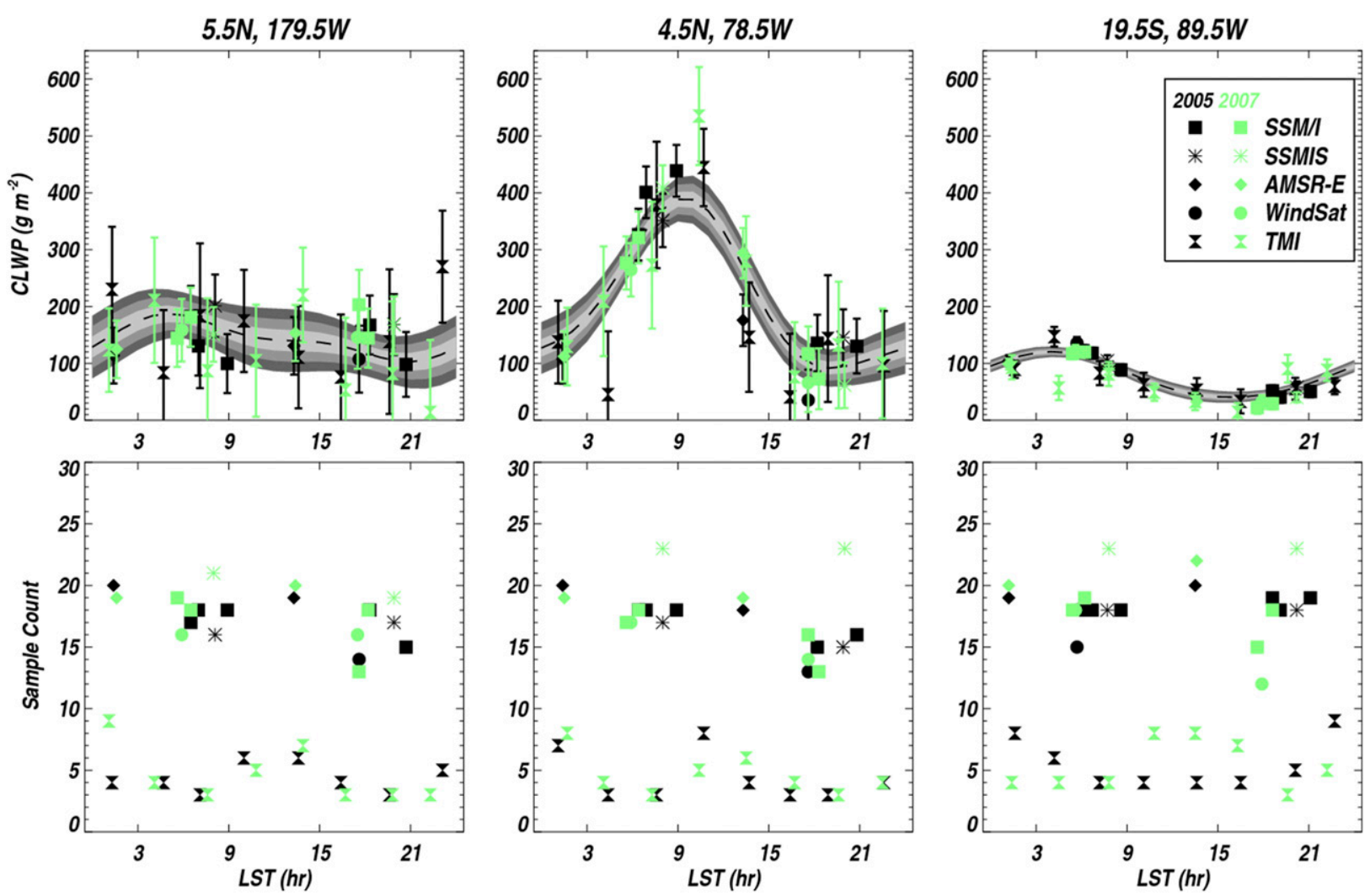

FIG. 4. (top) For different grid boxes and years, the satellite-sensor CLWP as a function of LST. Vertical errors bars for each CLWP observation are shown (see text for explanation). The best-fit diurnal cycle is overlain on each panel (dashed black line), with the 1-, 2- and 3-sigma errors (shades of gray) on the calculated best fits. (bottom) The corresponding numbers of samples going into the gridbox CLWP estimates.

statistical errors. The complete list of MAC-LWP data fields is shown in Table 2.

\section{Results}

\section{a. Mean state and diurnal cycle climatologies}

The CLWP and TLWP climatologies for the boreal winter and summer seasons are shown in Fig. 5. For the overlapping period terminating in December 2008, MAC CLWP systematically decreases by $10 \%-20 \%$ relative to the UWisc climatology over most low-cloud regimes; in fact, this decrease extends to nearly all locations where CLWP is less than $80 \mathrm{~g} \mathrm{~m}^{-2}$. The UWisc climatology was constructed using the version 6 RSS products. The currently used version 7 products were processed using a retrieval algorithm that included an improved water vapor continuum absorption model and beamfilling correction for rainfall retrieval (Wentz 2013). Such changes would impact CLWP via cross-talk issues that inevitably arise during the retrieval of multiple parameters. Perhaps more relevant for CLWP was the aforementioned removal of a clear-sky positive bias in cloud water that partly resulted from forcing negative CLWP retrievals to zero in the version 6 RSS products (Hilburn et al. 2010). Negative cloud water retrievals are a consequence of random errors in brightness temperatures producing negative cloud retrievals, and while unphysical, the forcing to zero led to a high-CLWP bias, especially in regions characterized by low-LWP clouds (e.g., stratocumulus, trade cumulus). This partly explains the pattern of differences found between MAC and UWisc in Fig. 5. Larger remaining MAC and UWisc differences are the result of the bias correction detailed in section $2 \mathrm{a}$ (and Fig. 2). Specifically, decreases of $5 \%-10 \%$ over the western Pacific, Indian Ocean, and intertropical convergence zone (ITCZ) regions and increases of $5 \%-20 \%$ over portions of the southern oceans and poleward of $40^{\circ} \mathrm{N}$ (including the midlatitude storm tracks) were found in the MAC climatology relative to a test product constructed without the empirical bias correction.

Figure 5 also shows the seasonal TLWP maps. As discussed, while low-frequency microwave attenuation is mostly proportional by liquid water mass, the dependence on DSD is not negligible. The assumption of a MarshallPalmer DSD is most reasonable for portions of the midlatitudes and most of the tropical oceans. Thus, the TLWP 
TABLE 2. MAC-LWP data fields provided in netCDF4 format. CLWP and TLWP fits are derived month by month for the 1988-2016 period for all oceanic grid boxes. The "order of fit" variable for every grid box is an integer that varies from 0 to 2 with the following meanings: 0 = (fit for CLWP mean only), 1 = (fit for CLWP mean and first harmonic), and 2 = (fit for CLWP mean and two harmonics). Term $M$ (in the covariance matrix) is the monthly mean fitted gridbox CLWP. Variances and covariances are monthly climatologies (i.e., currently 29-yr averages; thus, 12 values-January-December-for each grid box). Only boldface entries of the covariance matrix are made available (symmetric matrix). In the output files, off-diagonal elements of the covariance matrix are converted to correlations, and diagonal elements are converted to standard deviations.

\begin{tabular}{|c|c|c|c|c|}
\hline \multicolumn{5}{|c|}{ MAC-LWP data product } \\
\hline \multicolumn{3}{|c|}{ Ocean $1^{\circ}$ gridbox parameters } & Monthly & Jan-Dec, average over all years \\
\hline \multicolumn{3}{|l|}{ CLWP } & $\sqrt{ }$ & $\sqrt{ }$ \\
\hline \multicolumn{3}{|c|}{ CLWP $1 \sigma$ statistical error } & $\sqrt{ }$ & \\
\hline \multicolumn{3}{|c|}{ TLWP } & $\sqrt{ }$ & \\
\hline \multicolumn{3}{|c|}{ TLWP $1 \sigma$ statistical error } & $\sqrt{ }$ & \\
\hline \multicolumn{3}{|c|}{ First harmonic amplitude of CLWP $\left(\mathrm{A}_{1}\right)$} & & $\sqrt{ }$ \\
\hline \multicolumn{3}{|c|}{ First harmonic phase of CLWP $\left(\mathrm{T}_{1}\right)$} & & $\sqrt{ }$ \\
\hline \multicolumn{3}{|c|}{ Second harmonic amplitude of CLWP $\left(\mathrm{A}_{2}\right)$} & & $\sqrt{ }$ \\
\hline \multicolumn{3}{|c|}{ Second harmonic phase of CLWP $\left(\mathrm{T}_{2}\right)$} & & $\sqrt{ }$ \\
\hline \multicolumn{3}{|c|}{ Number of measurements } & & $\sqrt{ }$ \\
\hline \multicolumn{3}{|c|}{ Order of fit } & & $\sqrt{ }$ \\
\hline \multicolumn{4}{|c|}{ Covariance matrix information (only boldface entries below) } & $\sqrt{ }$ \\
\hline $\operatorname{corr}\left(M T_{2}\right)$ & $\operatorname{corr}\left(A_{1} T_{2}\right)$ & $\operatorname{corr}\left(T_{1} T_{2}\right)$ & $\operatorname{corr}\left(A_{2} T_{2}\right)$ & $\sigma_{\mathrm{T} 2}$ \\
\hline $\operatorname{corr}\left(M A_{2}\right)$ & $\operatorname{corr}\left(A_{1} A_{2}\right)$ & $\operatorname{corr}\left(T_{1} A_{2}\right)$ & $\sigma_{\mathrm{A} 2}$ & $\operatorname{corr}\left(A_{2} T_{2}\right)$ \\
\hline $\operatorname{corr}\left(M T_{1}\right)$ & $\operatorname{corr}\left(A_{1} T_{1}\right)$ & $\sigma_{T 1}$ & $\operatorname{corr}\left(T_{1} A_{2}\right)$ & $\operatorname{corr}\left(T_{1} T_{2}\right)$ \\
\hline $\operatorname{corr}\left(M A_{1}\right)$ & $\sigma_{A 1}$ & $\operatorname{corr}\left(A_{1} T_{1}\right)$ & $\operatorname{corr}\left(A_{1} A_{2}\right)$ & $\operatorname{corr}\left(A_{1} T_{2}\right)$ \\
\hline$\sigma_{M}$ & $\operatorname{corr}\left(M A_{1}\right)$ & $\operatorname{corr}\left(M T_{1}\right)$ & $\operatorname{corr}\left(M A_{2}\right)$ & $\operatorname{corr}\left(M T_{2}\right)$ \\
\hline
\end{tabular}

product is most reliable there. While uncertainty in TLWP still exists, the CLWP:TLWP ratio map (Fig. 5) allows the product user to determine where rainwater contribution to LWP is minimal. There is subjectivity in the ratio to use for filtering areas of lower confidence in the CLWP climatology. If we consider a ratio of $0.8^{2}$ as the metric for expressing our greatest confidence in the CLWP estimate, then most of the southern oceans, polar latitudes of the Northern Hemisphere, and nearly all of the trade cumulus and stratocumulus decks are included. The importance of these cloud regimes in determining cloud-climate feedbacks was discussed, and the availability of the TLWP field for use in establishing confidence in CLWP in such regions is a unique feature of the MAC-LWP product.

Global maps of CLWP statistical (i.e., random) errors and reduced chi-square $\left(\chi^{2}\right)$ are shown in Fig. 6. For presentation purposes, statistical errors are normalized by the monthly mean CLWP [averaged over all years and December-January (DFJ) or June-August (JJA), as indicated] and converted to percentage errors. As discussed in OWB08, these errors integrate down over longer periods, whereas systematic errors (e.g., cloud-rain partitioning), which are likely larger to begin with, would become more dominant. The $\chi^{2}$ map can be used for

\footnotetext{
${ }^{2}$ From OWB08 Fig. 4a, at the RSS instantaneous, pixel-level $\left(0.25^{\circ}\right)$ scale, a fraction of 0.8 corresponded to an average CLWP of $400 \mathrm{~g} \mathrm{~m}^{-2}$.
}

assessing the goodness of fit. The reduced $\chi^{2}$ is the standard chi-square estimate divided by the degrees of freedom $\left(N_{1}-N_{2}\right)$, where $N_{1}$ is the total number of CLWP $\left(Y_{i} \mathrm{LST}_{i}\right)$ measurements spanning 29 years (for any given grid box/month) and $N_{2}$ is the number of fit parameters (i.e., 33, or the number of years for which the monthly means are estimated plus the four diurnal cycle fit parameters). The reduced $\chi^{2}$ normalizes for the number of data points, which varies by geographic location, and thus we expect that the reduced $\chi^{2}$ should be $O(1)$.

Overall, for areas where the metric far exceeds unity, we can expect a poor fit-for example, Eq. (8) would not be a suitable choice for modeling the diurnal cycle-or an inappropriate estimation of intramonthly variability. In fact, there is some indication of reduced quality of fit in the subtropical stratocumulus regions that are characterized by high-amplitude diurnal cycles. However, the deviation from unity is small and the two-mode harmonic fit is sufficient for modeling CLWP across most oceanic regions. While within the expected bounds, the slight increase in $\chi^{2}$ across the $40^{\circ} \mathrm{S}-40^{\circ} \mathrm{N}$ domain reflects the use of TRMM data. For any given LST bin, TRMM samples any grid box a limited number of times per month. Thus, the TRMM diurnal cycle depiction is characterized by additional noise (also evident in Fig. 4) and the elevated $\chi^{2}$ reflects this. Portions of the Mediterranean Sea, during boreal summer, exhibit the highest $\chi^{2}$ values (2-4) found in the dataset. These regions and times of year are among the least 

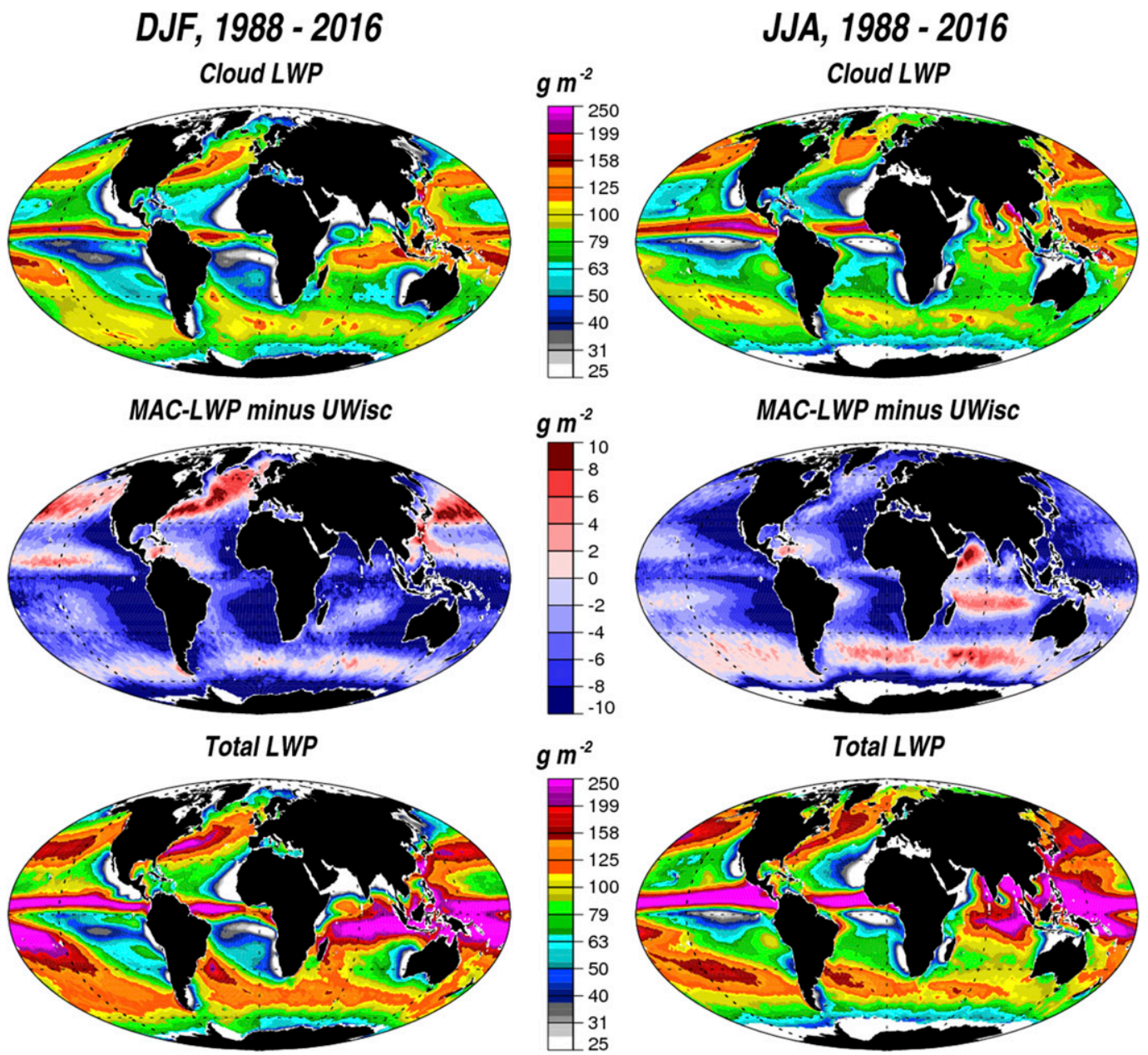

Total LWP

LWP Ratio (Cloud / Total)
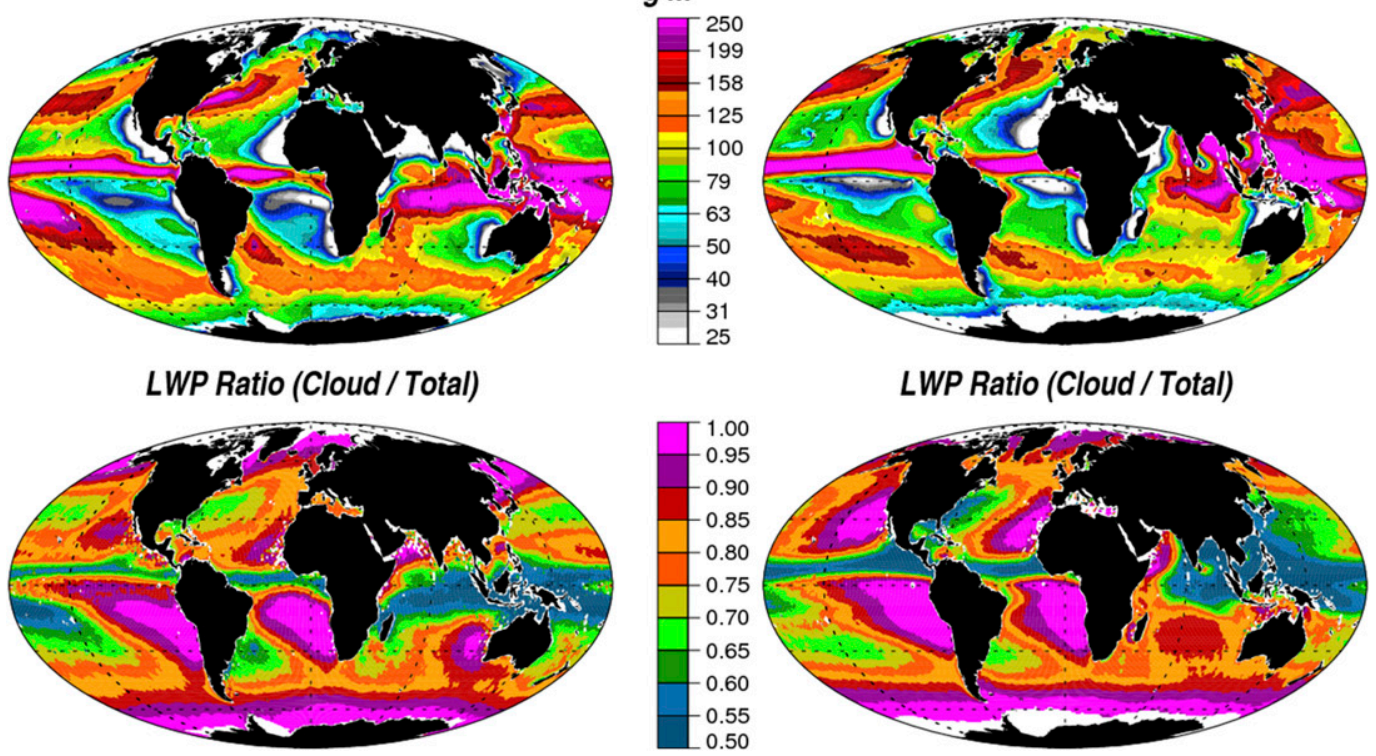

\section{LWP Ratio (Cloud / Total)}

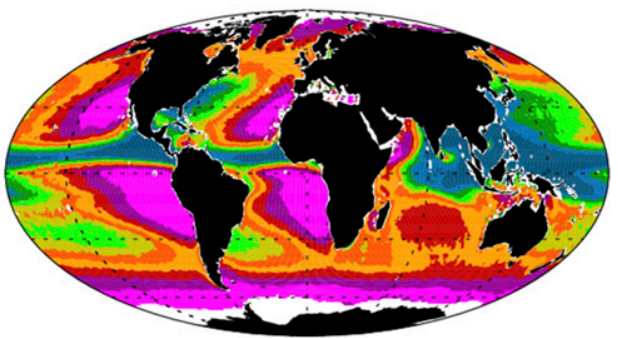

FIG. 5. (top to bottom) For the 29-yr record, the (left) DJF/(right) JJA average of CLWP, MAC CLWP minus the UWisc (OWB08) record for the overlapping 1988-2008 period, the TLWP, and the ratio of CLWP:TLWP.

cloudy locations in the MAC-LWP dataset; in terms of monthly CLWP, magnitudes are often less than $10 \mathrm{~g} \mathrm{~m}^{-2}$. An investigation of the input RSS satellite datasets for grid boxes in this region show that for nearly all LSTs, CLWP is often negligible; therefore, intramonthly variability is negligible too. However, there are small systematic biases between the datasets $\left(\sim 1-5 \mathrm{~g} \mathrm{~m}^{-2}\right)$, and therefore because the intramonthly variability is nearly zero, there is a large penalty for any departure of the fit from any individual sensor CLWP estimate. This leads to a larger $\chi^{2}$ estimate in these regions.

Figure 7 shows MAC CLWP diurnal cycle information, which is useful for process-level studies and particularly useful for assessing model-simulated diurnal cycles. Consistent with what was shown in OWB08, the normalized amplitude of the diurnal cycle first harmonic is greatest near coastal regions, and across the South American and Namibian stratocumulus decks. The amplitude is larger 

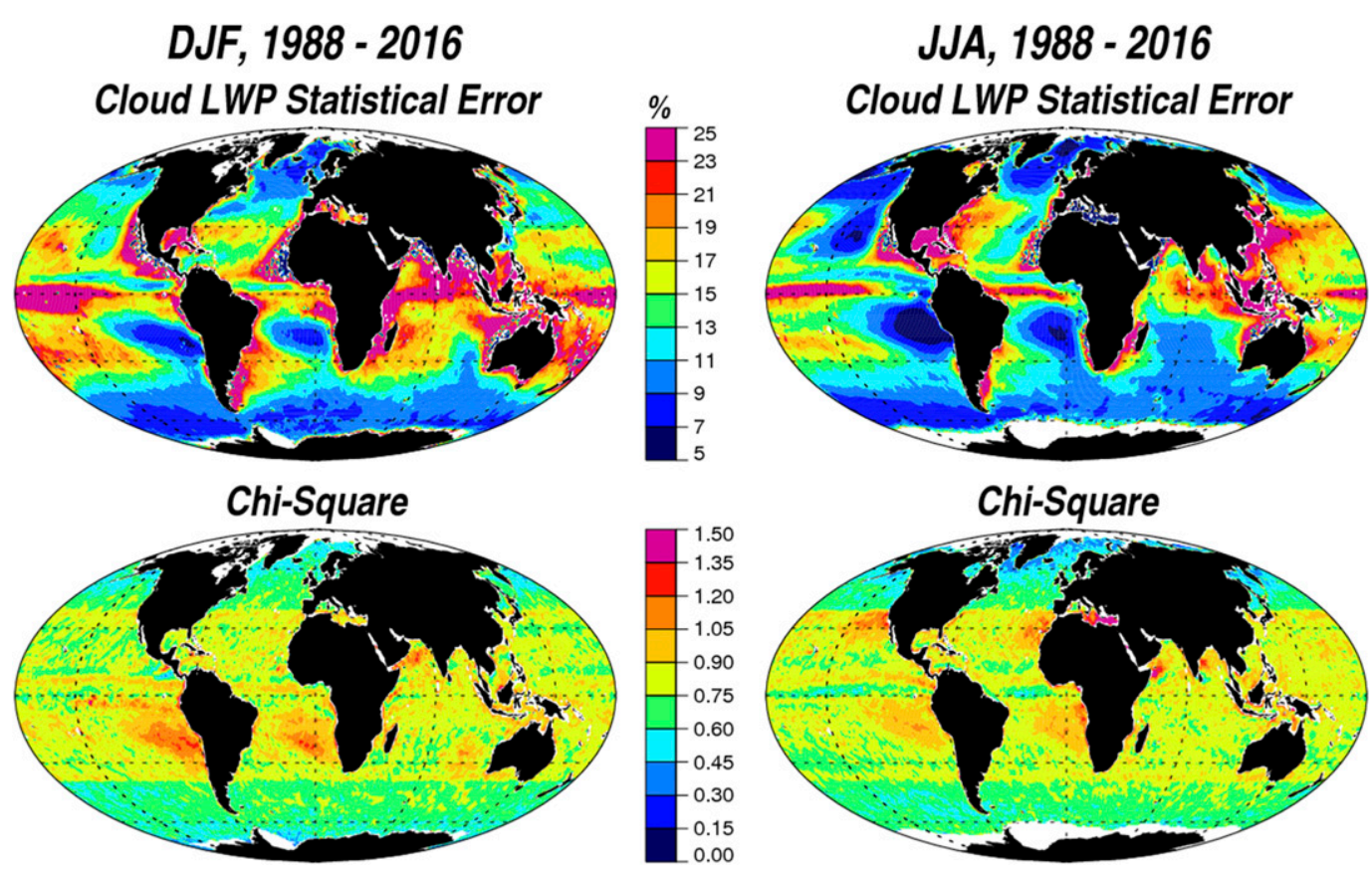

FIG. 6. (top to bottom) For (left) DJF/(right) JJA 1988-2016, the average monthly statistical error on fitted CLWP, and the chi-square metric for assessing the goodness of fit between the observed CLWP and the assumed harmonic fits.

than the semidiurnal (second) harmonic amplitude. While the second harmonic amplitude is greatest near coastal regions, it is commonly nonzero over the open oceans. We discussed that sensors observing a grid box at varying times of the day may be expected to disagree with each other if the cloud diurnal cycle is best described with the inclusion of a nonzero second harmonic sinusoid. In the following section, we assess some of the impacts of the second harmonic on the multisensor record construction.

\section{b. Diurnal cycle correction impacts on individual sensor CLWP and trend computations}

Consider two sensors [Special Sensor Microwave Imager (SSM/I) F13 and F14] whose LST records trend relative to each other over their common shared-time period (Fig. 1, and bottom panels of Fig. 8). The tropical-average and two regional-averaged CLWP records associated with each sensor are shown in the top-left three panels of Fig. 8. Note that a product creation technique that would entail a straight (or sample count weighted) average of these two records would give an artificial upward trend in CLWP over the period, since the two records approach each other toward the end of the period due to the positive trend of SSM/I F14. The diurnal cycle corrected CLWP records are shown in the top-right three panels of Fig. 8. Note that a diurnal cycle correction [which, on a sensor-by-sensor basis, is performed through subtraction of the Eq. (8) fit at every month/year/grid box] yields two sensor CLWP records that barely exhibit any intersensor trends. Therefore, an average of the two records would yield a CLWP record that does not trend with time. These results demonstrate the value of the framework utilized for creating the multidecadal, multisensor CDR.

These results further suggest that the observed CLWP record-including trend computations-may be different depending on whether the diurnal cycle correction was taken into account. But, to what extent is a diurnal cycle correction affecting trends? In Fig. 9, we show the CLWP trend maps for MAC-LWP and the trend map for a record created by simply averaging all sensor products together (where each is weighted by the number of samples). Our focus is only on trends and time series in regions for which we have high confidence in the CLWP estimates (i.e., CLWP:TLWP ratio is $>0.8$ ) and where trends were identified as statistically significant at the 95\% level (using the methodology of Santer et al. 2000). Note that we are not arguing the physical causes of trends or the significance of trends; instead, we are investigating only the effect of the diurnal cycle correction to infer to what extent our correction impacts the overall record. Instead of large changes in CLWP time series and trends, we find that our accounting of the diurnal cycle mostly impacts the CLWP record prior to 1993 (e.g., highlighted boxes in Fig. 9), which is the period when only two SSM/I sensors were observing Earth (Fig. 1). This period is analogous to our discussion of the two SSM/I sensors in 

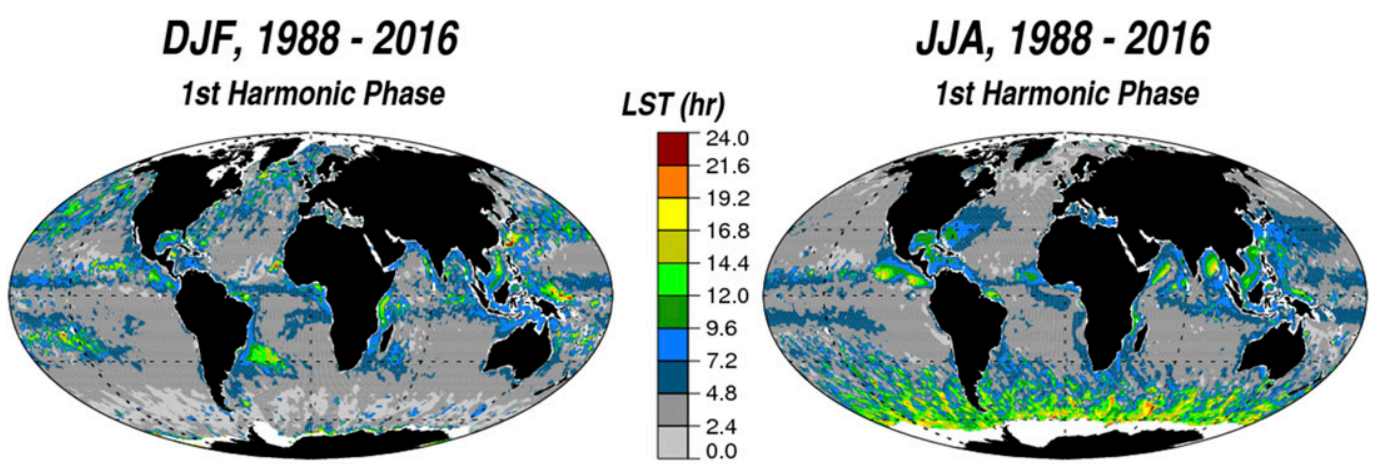

1st Harmonic Normalized Amplitude
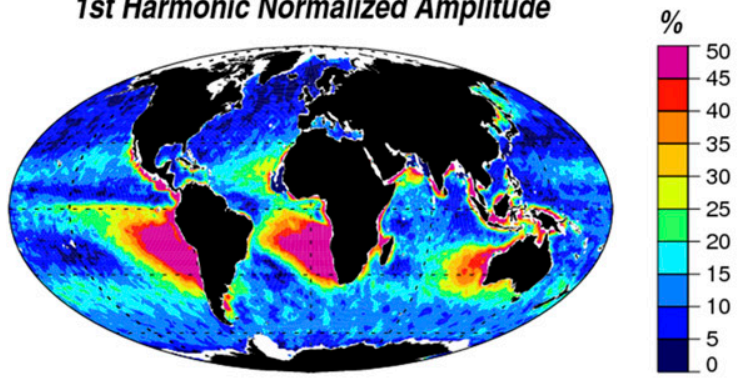

1st Harmonic Normalized Amplitude

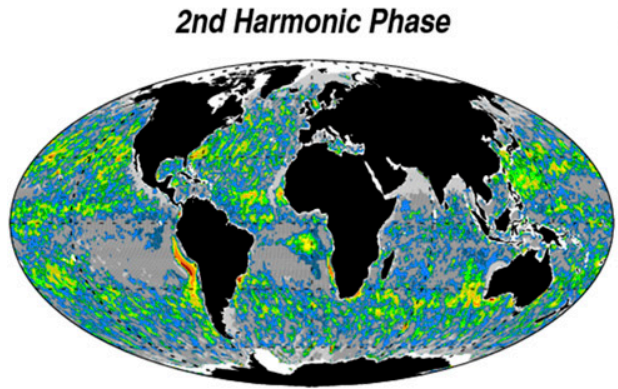

LST (hr)
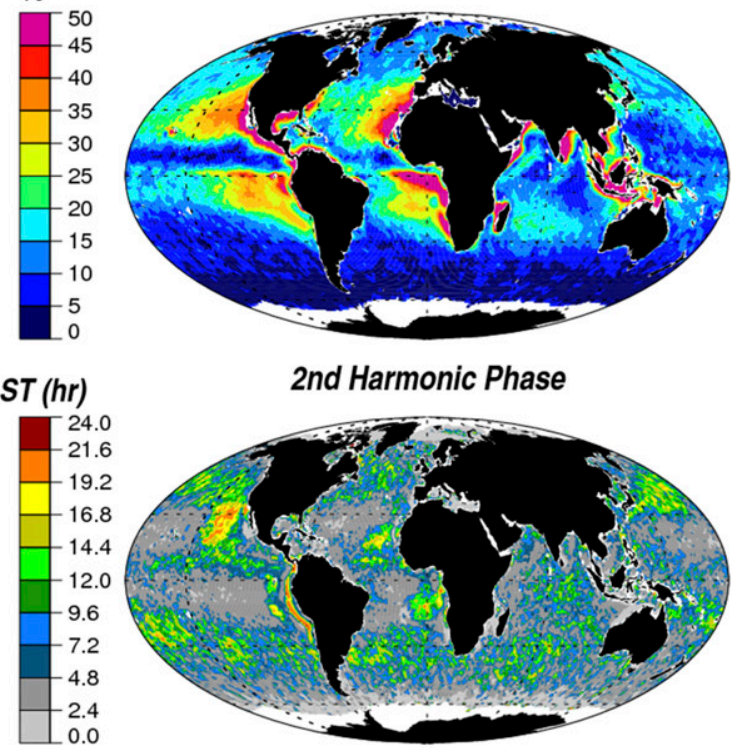

2nd Harmonic Normalized Amplitude
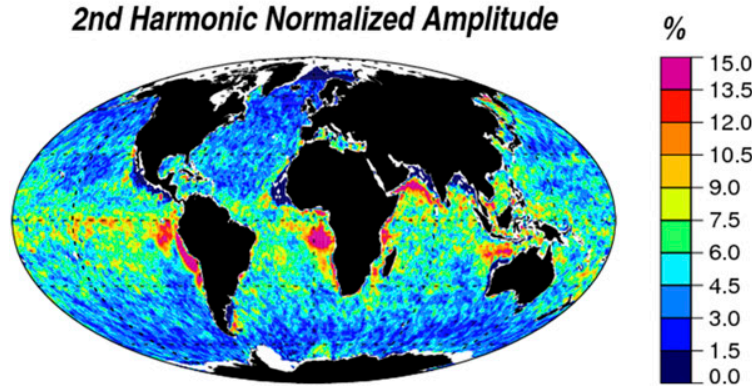

2nd Harmonic Normalized Amplitude

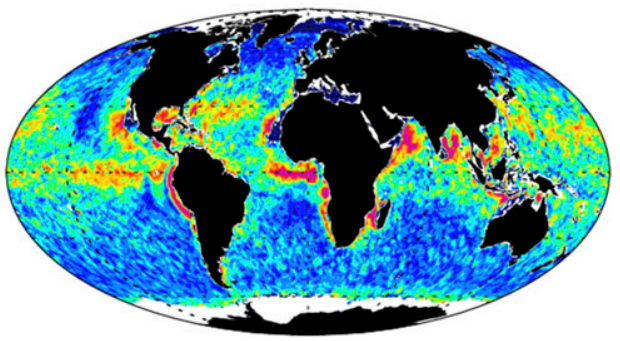

FIG. 7. (top to bottom) For the 29-yr record, the (left) DJF/(right) JJA average first harmonic phase (i.e., LST of the maximum first harmonic fitted CLWP), average first harmonic normalized amplitude (actual amplitude divided by the average CLWP), average phase of the second harmonic, and average second harmonic normalized amplitude.

Fig. 8, which we can consider to be a limiting case where few orbiting satellites implies greater discrepancy in CLWP before and after a diurnal cycle correction. For the box 1 region of Fig. 9, which comprises two negative trend bull's-eyes in the Pacific Ocean off the immediate west coast of South America, the amplitude of the second harmonic of the diurnal cycle was among the highest found (Fig. 7). After the diurnal cycle correction was applied, the negative trends were no longer statistically significant. As for the physical cause of a bimodal diurnal cycle, the increased second harmonic amplitude may be attributed to the superposition of diurnal cycles in solar heating and vertical velocity (Garreaud and Muñoz 2004). For a detailed discussion on the impact of solar heating on CLWP in this region, see Wood et al. (2009, and in particular their Fig. 6). 

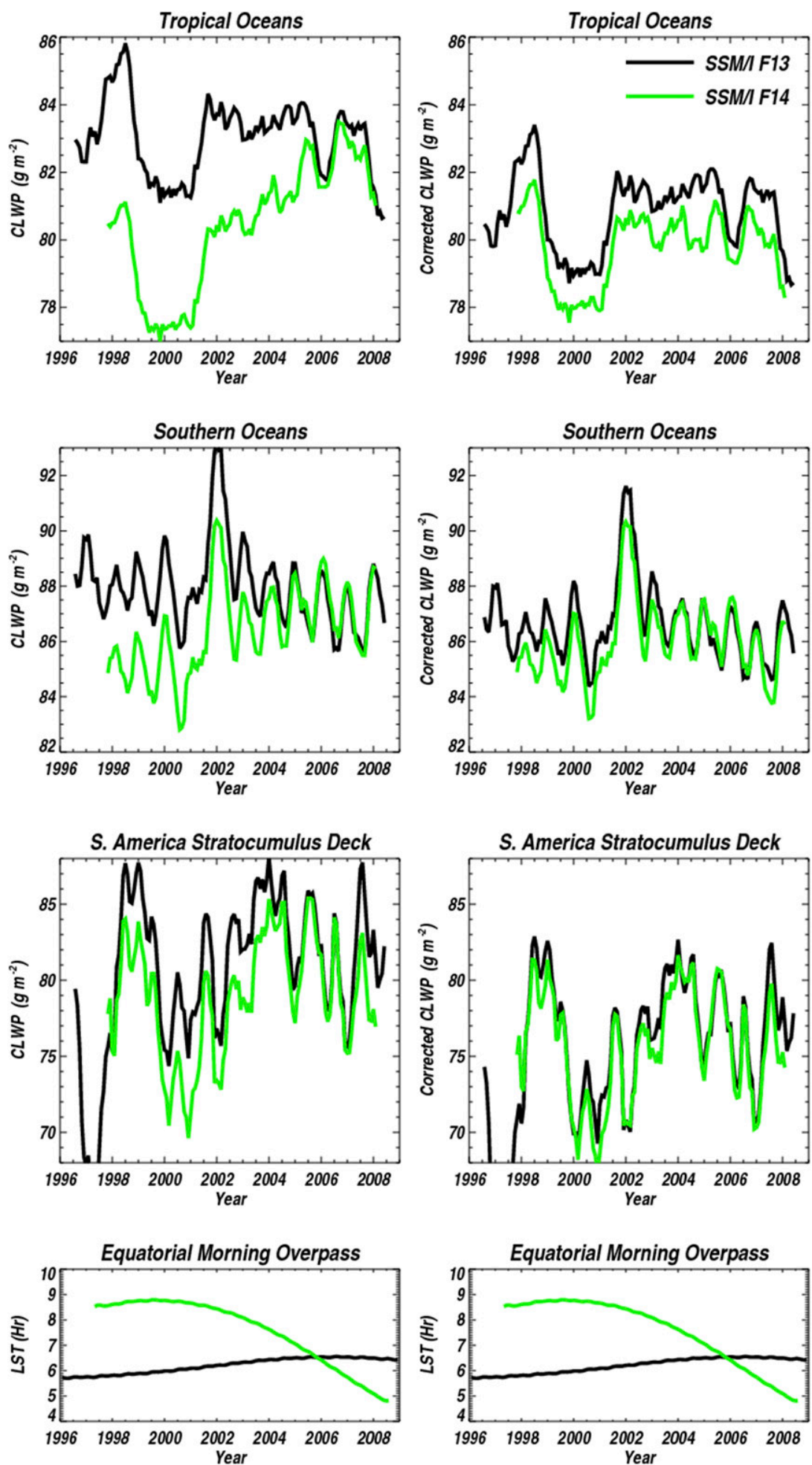

FIG. 8. (top to bottom) Original SSM/I sensor (from RSS) CLWP as a function of year for the tropical ocean belt $\left(40^{\circ} \mathrm{S}-40^{\circ} \mathrm{N}\right)$, the Southern Oceans $\left(60^{\circ}-45^{\circ} \mathrm{S}\right)$, the South America stratocumulus deck $\left(20^{\circ}-12^{\circ} \mathrm{S}, 271^{\circ}-281^{\circ} \mathrm{E}\right)$, and the corresponding morning equatorial overpass times (LSTs) for the two sensors. (right) As in (left), except that the satellite records have been corrected for diurnal cycle effects using the MAC-LWP diurnal cycle amplitude/phase information. The equatorial overpass time panel has been repeated to aid in visual interpretation. 

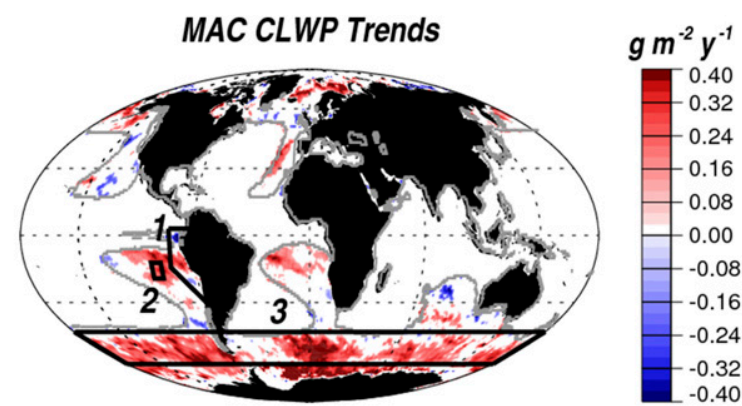

Uncorrected CLWP Trends
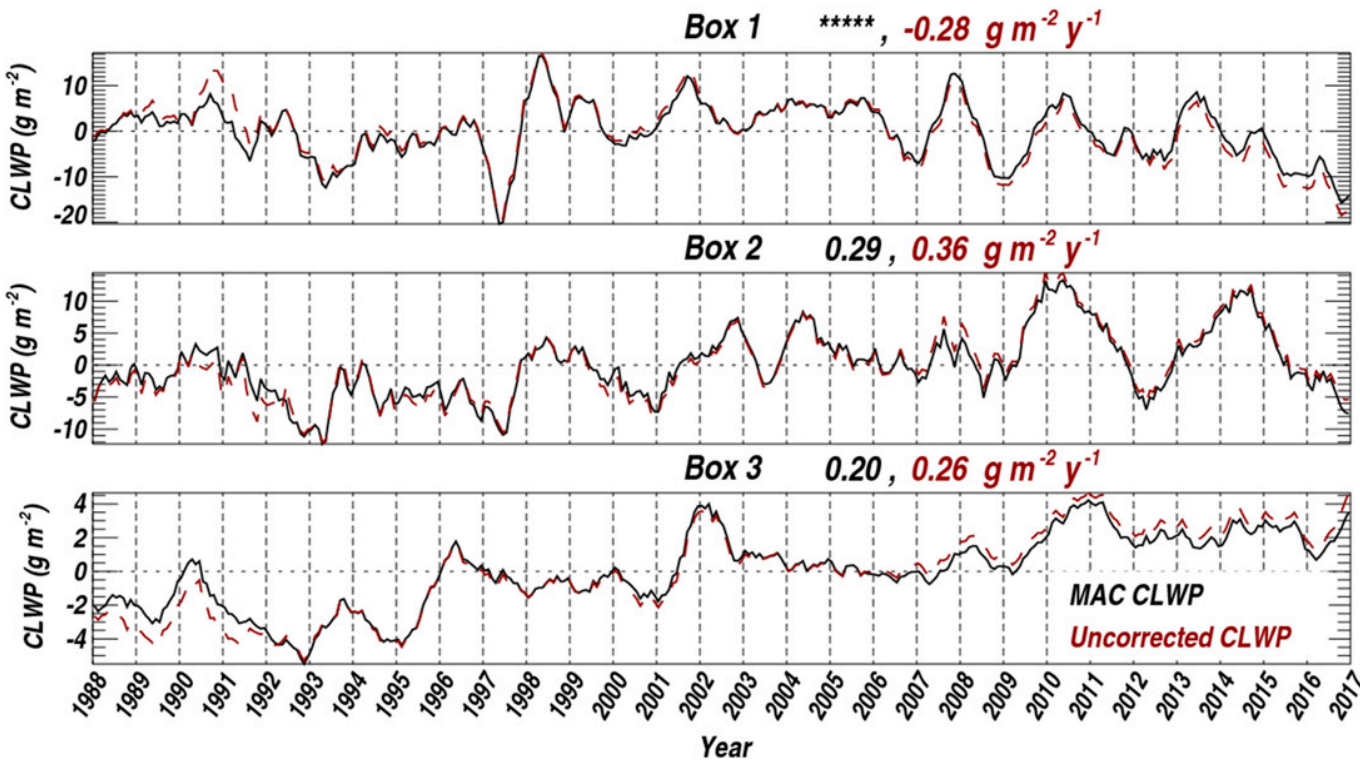

FIG. 9. (top) The 29-yr CLWP trends from MAC-LWP and a proof-of-concept dataset (i.e., "uncorrected") that assumes no diurnal cycle when the satellite products are merged. The boundary is drawn where the CLWP:TLWP ratio falls below 0.8 (light gray line; wide swaths of white). Inside the boundary, only regions for which trends are significant at the $95 \%$ level are shaded. (bottom) CLWP time series from the MAC-LWP and uncorrected datasets: comprising two $<0 \mathrm{~g} \mathrm{~m}^{-2} \mathrm{y}^{-1}$ trend bull's-eyes in the strip off the west coast of South America (where the second harmonic normalized amplitude exceeds $12 \%$ in Fig. 7; box 1); comprising the southeast Pacific stratocumulus deck (box 2), and covering the southern oceans $\left(60^{\circ}-45^{\circ} \mathrm{S}\right.$; box 3$)$. For all panels, the seasonal cycle in CLWP has been removed. Computed trends for each box (color coded by dataset) are listed at the top of each time series panel. CLWP trends for MAC are not statistically significant in box 1 and are masked out with asterisks.

Fortuitously perhaps, it appears that for the remainder of the 29-yr record, enough satellites were observing Earth at various LSTs to effectively "resolve" the diurnal cycle in a manner that the average is nearly unbiased, and trend computations are minimally affected (mostly, a slight decrease in magnitudes for all regions characterized by positive trends). Figure 4 supports this claim as well, where we find that rarely does $3 \mathrm{~h}$ pass without a passive microwave observation (especially over the $40^{\circ} \mathrm{S}-40^{\circ} \mathrm{N}$ domain).

\section{Applications and relevance to climate research}

Perhaps the most notable development relative to the UWisc CLWP climatology is the derivation and inclusion of the TLWP field. As mentioned, since lower-frequency microwave brightness temperatures are more directly related to total liquid water attenuation (Seethala and Horváth 2010), production of the TLWP field requires no assumptions about cloud-rain partitioning. Analyses and composites of variations in TLWP can now be performed for long periods over expansive raining areas [e.g., ITCZ, South Pacific convergence zone (SPCZ), and midlatitude cyclone track] relative to what was reliably characterized by CLWP. The inclusion of GPM GMI (not available in UWisc) allows for increased sampling in the higher latitudes, which will prove more useful for the study of midlatitude cyclones, especially from mid-2014 onward. The multidecadal record of TLWP will be useful for analyses of total liquid water content variations during phases of El Niño-Southern Oscillation (ENSO), given that such modes of atmospheric variability are associated 
with large variations in rainfall. TLWP is made available at a time in GCM development when prognostic precipitation (e.g., Gettelman and Morrison 2015) is becoming more prevalent. By combining the GCM cloud water and rainwater fields, an evaluation of GCM simulation of total liquid water path in tropical and midlatitude raining zones can be performed [e.g., for a CLWP evaluation of GCMs, see Lauer and Hamilton (2013)].

In terms of CLWP, the MAC-LWP record is a substantial upgrade relative to UWisc, since it extends the UWisc record length by nearly 10 years, includes all the latest version RSS datasets, thus mitigating CLWP biases further (as explained in this manuscript), and includes a CLWP clear-sky bias correction (see Fig. 5 for climatological differences between MAC and UWisc). Analyses of CLWP in conjunction with TLWP should prove useful for quantifying the liquid component of mixed-phase clouds and will further our understanding of how such clouds are changing over the high-latitude southern oceans (e.g., McCoy et al. 2016). The near-30-yr record supports longer CLWP trend-evaluation studies (e.g., Norris et al. 2016; Manaster et al. 2017). The alternative use of the TLWP field as a quality-control field allows climate researchers to screen for areas where the CLWP estimates are most reliable. While the exact CLWP: TLWP ratio to use for the highest quality is somewhat subjective, our analyses have shown that a ratio of 0.8 is a reasonable start. The MAC-LWP record provides diurnal cycle climatologies for each month of the year, and an analysis of these cycles in conjunction with the CLWP: TLWP ratio field can allow for an important evaluation of observed and model-simulated shallow clouds at nearprocess-level scales.

\section{Summary and future plans}

Currently, the MAC-LWP product aggregates 14 passive microwave retrieval products. Particular effort has been paid toward correcting microwave biases in regions for which CLWP estimates derived from optical imagers are trustworthy. Overall, the bias-corrected CLWP field, used in concert with the TLWP field and statistical uncertainty estimates, allows the user to isolate wide regions characterized by high-quality CLWP estimates: the southern oceans, large portions of the North Atlantic and North Pacific Oceans, and nearly all shallow cumulus and stratocumulus regimes.

Independent of statistical significance and physical causes of any CLWP trends, we provided evidence that the time series of CLWP are largely independent of the diurnal cycle correction. While not discussed, we have investigated alternate approaches for diurnal cycle correction that included looking at deriving harmonic amplitudes/phases varying not only as a function of month but as a function of large-scale mode of atmospheric variability [e.g., ENSO or Pacific decadal oscillation (PDO)]. The impact on the CLWP time series was minimal, which is not surprising, since the small differences we see in Fig. 9 are expected to be at the upperlimit bound because we are comparing MAC-LWP to a record with no diurnal cycle correction.

With less focus on how we perform a diurnal cycle correction, a key future goal in the production and maintenance of the MAC-LWP record now centers on increasing our understanding of-and correction ofremaining regional- or environment-dependent biases in CLWP. This will include quantifying biases arising from not accounting for CLWP variability within the microwave sensors' fields of view (FOVs) (Bremen et al. 2002; Rapp et al. 2009), biases arising from errors in the assumed emission temperature of the cloud (Seethala and Horváth 2010), and biases arising from the assumed partitioning in rain and cloud water [mostly an issue for deeper clouds but rainfall in low, warm cloud fields occurs as well (e.g., Stevens et al. 2005; Wood et al. 2008; Lebsock and L'Ecuyer 2011)]. For now, the use of the TLWP field in screening regions for which the ratio of CLWP:TLWP is small remains the best way to evade the rain-cloud partitioning issue.

Analyses involving collocated, independent A-Train data (MODIS, CALIPSO, and CloudSat) and ship-based upward-looking radiometer retrievals are currently underway toward addressing the aforementioned biases. While independent clear-sky MODIS observations were important for evaluating our product in clear-sky scenes, the MACLWP bias-corrected product remains unvalidated in partially cloudy through overcast scenes. The Marine ARM GEWEX Cloud System Studies (GCSS) Pacific CrossSection Intercomparison (GPCI) Investigation of Clouds (MAGIC; Lewis and Teixeira 2015) upward-looking radiometer dataset (e.g., Painemal et al. 2016), and any future shipborne radiometer and radar measurements, may be exploited in non-clear-sky scenes to provide additional validation of the product (assuming appropriate field of view/spatial and temporal averaging methods enabling the best evaluations are developed). CloudSat, given its sensitivity to rainwater (L'Ecuyer and Stephens 2002; Lebsock and L'Ecuyer 2011), will be particularly useful in addressing the cloud-rain partitioning problem.

The MAC-LWP data product ${ }^{3}$ (in netCDF4 format), along with associated documentation, is available at

\footnotetext{
${ }^{3}$ The CLWP clear-sky bias correction lookup table produced from Eq. (1) (section 2a) may also be obtained by sending an e-mail query to the corresponding author.
} 
the Goddard Earth Sciences Data and Information Services Center (GES DISC, current hosting: http:// disc.sci.gsfc.nasa.gov).

Acknowledgments. MAC-LWP, an enhanced climate data record (CDR), is funded through the NASA Making Earth System Data Records for Use in Research Environments (MEaSUREs) Program under RTOP WBS 105324/547714.04.14.01.54. GE is funded via a subcontract with the Jet Propulsion Laboratory (JPL) (Grant GG008658). A portion of the research described in this paper was carried out at the Jet Propulsion Laboratory, California Institute of Technology, under contract with NASA. We thank Kyle Hilburn and three anonymous reviewers for their helpful comments on the manuscript. All passive microwave datasets used in MAC-LWP construction were produced by Remote Sensing Systems (RSS): TMI is sponsored by the NASA Earth Sciences Program, AMSR-E is sponsored by the NASA AMSR-E Science Team, WindSat and GMI are sponsored by the NASA Earth Physical Oceanography Program, and AMSR-2 is sponsored by the NASA Stand Alone Mission of Opportunity (SALMON) program. RSS data are available online (at www.remss.com/ missions).

\section{REFERENCES}

Bennartz, R., and G. W. Petty, 2001: The sensitivity of microwave remote sensing observations of precipitation to ice particle size distributions. J. Appl. Meteor., 40, 345-364, doi:10.1175/ 1520-0450(2001)040<0345:TSOMRS > 2.0.CO; 2 .

— and P. Bauer, 2003: Sensitivity of microwave radiances at 85$183 \mathrm{GHz}$ to precipitating ice particles. Radio Sci., 38, 8075, doi:10.1029/2002RS002626.

_ _ P. Watts, J. F. Meirink, and R. Roebeling, 2010: Rainwater path in warm clouds derived from combined visible/near-infrared and microwave satellite observations. J. Geophys. Res., 115, D19120, doi:10.1029/2009JD013679.

Berg, W., T. L'Ecuyer, and C. Kummerow, 2006: Rainfall climate regimes: The relationship of regional TRMM rainfall biases to the environment. J. Appl. Meteor. Climatol., 45, 434-454, doi:10.1175/JAM2331.1.

Bony, S., and J.-L. Dufresne, 2005: Marine boundary layer clouds at the heart of tropical cloud feedback uncertainties in climate models. Geophys. Res. Lett., 32, L20806, doi:10.1029/ 2005 GL023851.

Boucher, O., and Coauthors, 2013: Clouds and aerosols. Climate Change 2013: The Physical Science Basis, T. F. Stocker et al., Eds., Cambridge University Press, 571-657.

Bremen, L. V., E. Ruprecht, and A. Macke, 2002: Errors in liquid water path retrieval arising from cloud inhomogeneities: The beam-filling effect. Meteor. Z., 11, 13-19, doi:10.1127/ 0941-2948/2002/0011-0013.

Elsaesser, G. S., and C. D. Kummerow, 2008: Toward a fully parametric retrieval of the nonraining parameters over the global oceans. J. Appl. Meteor. Climatol., 47, 1599-1618, doi:10.1175/2007JAMC1712.1.
, C. W. O'Dell, and J. Teixeira, 2015: Multi-Sensor Advanced Climatology of Liquid Water Path (MAC-LWP). NASA MEaSUREs Algorithm Theoretical Basis Doc., 15 pp.

Eyring, V., S. Bony, G. A. Meehl, C. A. Senior, B. Stevens, R. J. Stouffer, and K. E. Taylor, 2016: Overview of the Coupled Model Intercomparison Project Phase 6 (CMIP6) experimental design and organization. Geosci. Model Dev., 9, 19371958, doi:10.5194/gmd-9-1937-2016.

Garreaud, R. D., and R. Muñoz, 2004: The diurnal cycle in circulation and cloudiness over the subtropical southeast Pacific: A modeling study. J. Climate, 17, 1699-1710, doi:10.1175/ 1520-0442(2004)017<1699:TDCICA > 2.0.CO;2.

Ge, J., J. Huang, F. Weng, and W. Sun, 2008: Effects of dust storms on microwave radiation based on satellite observation and model simulation over the Taklamakan desert. Atmos. Chem. Phys., 8, 4903-4909, doi:10.5194/acp-8-4903-2008.

Gettelman, A., and H. Morrison, 2015: Advanced two-moment microphysics for global models. Part I: Off-line tests and comparisons with other schemes. J. Climate, 28, 1268-1287, doi:10.1175/JCLI-D-14-00102.1.

Greenwald, T. J., 2009: A 2 year comparison of AMSR-E and MODIS cloud liquid water path observations. Geophys. Res. Lett., 36, L20805, doi:10.1029/2009GL040394.

— T. S. L'Ecuyer, and S. A. Christopher, 2007: Evaluating specific error characteristics of microwave-derived cloud liquid water products. Geophys. Res. Lett., 34, L22807, doi:10.1029/2007GL031180.

Hilburn, K. A., and F. J. Wentz, 2008: Intercalibrated passive microwave rain products from the Unified Microwave Ocean Retrieval Algorithm (UMORA). J. Appl. Meteor. Climatol., 47, 778-794, doi:10.1175/2007JAMC1635.1.

$\longrightarrow,-$ C. Mears, T. Meissner, and D. Smith, 2010: Description of remote sensing systems version-7 geophysical retrievals. 17th Conf. on Satellite Meteorology and Oceanography, Annapolis, MD, Amer. Meteor. Soc., JP1.5, https://ams.confex. com/ams/17Air17Sat9Coas/webprogram/Paper174339.html.

IPCC, 2007: Climate Change 2007: The Physical Science Basis. Cambridge University Press, 996 pp.

Klein, S. A., and D. L. Hartmann, 1993: The seasonal cycle of low stratiform clouds. J. Climate, 6, 1587-1606, doi:10.1175/ 1520-0442(1993)006<1587:TSCOLS > 2.0.CO;2.

Lauer, A., and K. Hamilton, 2013: Simulating clouds with global climate models: A comparison of CMIP5 results with CMIP3 and satellite data. J. Climate, 26, 3823-3845, doi:10.1175/JCLI-D-12-00451.1.

Lebsock, M. D., and T. S. L'Ecuyer, 2011: The retrieval of warm rain from CloudSat. J. Geophys. Res., 116, D20209, doi:10.1029/2011JD016076.

- and H. Su, 2014: Application of active spaceborne remote sensing for understanding biases between passive cloud water path retrievals. J. Geophys. Res. Atmos., 119, 8962-8979, doi:10.1002/2014JD021568.

L'Ecuyer, T. S., and G. L. Stephens, 2002: An estimation-based precipitation retrieval algorithm for attenuation radars. J. Appl. Meteor., 41, 272-285, doi:10.1175/1520-0450(2002)041<0272: AEBPRA $>2.0 . \mathrm{CO} ; 2$

Lewis, E. R., and J. Teixeira, 2015: Dispelling clouds of uncertainty. Eos, Trans. Amer. Geophys. Union, 96, doi:10.1029/ 2015EO031303.

Liu, G., and J. A. Curry, 1993: Determination of characteristic features of cloud liquid water from satellite microwave measurements. J. Geophys. Res., 98, 5069-5092, doi:10.1029/92JD02888.

Manaster, A., C. W. O'Dell, and G. Elsaesser, 2017: Evaluation of cloud liquid water path trends using a multidecadal record of 
passive microwave observations. J. Climate, 30, 5871-5884, doi:10.1175/JCLI-D-16-0399.1.

McCoy, D. T., I. Tan, D. L. Hartmann, M. D. Zelinka, and T. Storelvmo, 2016: On the relationships among cloud cover, mixed-phase partitioning, and planetary albedo in GCMs. J. Adv. Model. Earth Syst., 8, 650-668, doi:10.1002/2015MS000589.

Mears, C. A., D. K. Smith, and F. J. Wentz, 2001: Comparison of Special Sensor Microwave Imager and buoy-measured wind speeds from 1987 to 1997. J. Geophys. Res., 106, 11 719-11 730, doi:10.1029/1999JC000097.

Meissner, T., and F. J. Wentz, 2012: The emissivity of the ocean surface between 6 and $90 \mathrm{GHz}$ over a large range of wind speeds and Earth incidence angles. IEEE Trans. Geosci. Remote Sens., 50, 3004-3026, doi:10.1109/TGRS.2011.2179662.

_ D. Smith, and F. Wentz, 2001: A 10-year intercomparison between collocated Special Sensor Microwave Imager oceanic surface wind speed retrievals and global analyses. J. Geophys. Res., 106, 11 731-11 742, doi:10.1029/1999JC000098.

Norris, J. R., R. J. Allen, A. T. Evan, M. D. Zelinka, C. W. O'Dell, and S. A. Klein, 2016: Evidence for climate change in the satellite cloud record. Nature, 536, 72-75, doi:10.1038/ nature 18273 .

O’Dell, C. W., F. J. Wentz, and R. Bennartz, 2008: Cloud liquid water path from satellite-based passive microwave observations: A new climatology over the global oceans. J. Climate, 21, 1721-1739, doi:10.1175/2007JCLI1958.1.

Painemal, D., T. Greenwald, M. Cadeddu, and P. Minnis, 2016: First extended validation of satellite microwave liquid water path with ship-based observations of marine low clouds. Geophys. Res. Lett., 43, 6563-6570, doi:10.1002/2016GL069061.

Petty, G. W., 1994: Physical retrievals of over-ocean rain rate from multichannel microwave imagery. Part II: Algorithm implementation. Meteor. Atmos. Phys., 54, 101-121, doi:10.1007/ BF01030054.

Platnick, S., M. D. King, S. A. Ackerman, W. P. Menzel, B. A. Baum, J. C. Riedi, and R. A. Frey, 2003: The MODIS cloud products: Algorithms and examples from Terra. IEEE Trans. Geosci. Remote Sens., 41, 459-473, doi:10.1109/ TGRS.2002.808301.

—_ and Coauthors, 2015: MODIS Atmosphere L3 Daily Product. NASA MODIS Adaptive Processing System, Goddard Space Flight Center, accessed 5 April 2017, doi:10.5067/MODIS/ MYD08_D3.006.

Rapp, A. D., M. Lebsock, and C. Kummerow, 2009: On the consequences of resampling microwave radiometer observations for use in retrieval algorithms. J. Appl. Meteor. Climatol., 48, 1981-1993, doi:10.1175/2009JAMC2155.1.

Reynolds, R. W., N. A. Rayner, T. M. Smith, D. C. Stokes, and W. Wang, 2002: An improved in situ and satellite SST analysis for climate. J. Climate, 15, 1609-1625, doi:10.1175/ 1520-0442(2002)015<1609:AIISAS>2.0.CO;2.

Santer, B. D., T. Wigley, J. Boyle, D. Gaffen, J. Hnilo, D. Nychka, D. Parker, and K. Taylor, 2000: Statistical significance of trends and trend differences in layer-average atmospheric temperature time series. J. Geophys. Res., 105, 7337-7356, doi:10.1029/1999JD901105.

Seethala, C., and Á. Horváth, 2010: Global assessment of AMSR-E and MODIS cloud liquid water path retrievals in warm oceanic clouds. J. Geophys. Res., 115, D13202, doi:10.1029/ 2009JD012662.

Soden, B. J., and I. M. Held, 2006: An assessment of climate feedbacks in coupled ocean-atmosphere models. J. Climate, 19, 3354-3360, doi:10.1175/JCLI3799.1.

Stephens, G. L., 2005: Cloud feedbacks in the climate system: A critical review. J. Climate, 18, 237-273, doi:10.1175/ JCLI-3243.1.

Stevens, B., G. Vali, K. Comstock, R. Wood, M. Van Zanten, P. H. Austin, D. H. Bretherton, and C. S. Lenschow, 2005: Pockets of open cells and drizzle in marine stratocumulus. Bull. Amer. Meteor. Soc., 86, 51-57, doi:10.1175/BAMS-86-1-51.

Trenberth, K. E., J. Fasullo, and L. Smith, 2005: Trends and variability in column-integrated atmospheric water vapor. Climate Dyn., 24, 741-758, doi:10.1007/s00382-005-0017-4.

Waliser, D. E., and W. Zhou, 1997: Removing satellite equatorial crossing time biases from the OLR and HRC datasets. J. Climate, 10, 2125-2146, doi:10.1175/1520-0442(1997)010<2125: RSECTB $>2.0 . C O ; 2$.

Wentz, F. J., 1997: A well-calibrated ocean algorithm for special sensor microwave imager. J. Geophys. Res., 102, 8703-8718, doi:10.1029/96JC01751.

_ 2013: SSM/I version-7 calibration report. RSS Tech. Rep. 011012, 46 pp., http://images.remss.com/papers/tech_reports/ 2012_Wentz_011012_Version-7_SSMI_Calibration.pdf.

_ 2015: A 17-yr climate record of environmental parameters derived from the Tropical Rainfall Measuring Mission (TRMM) microwave imager. J. Climate, 28, 6882-6901, doi:10.1175/JCLI-D-15-0155.1.

, and R. W. Spencer, 1998: SSM/I rain retrievals within a unified all-weather ocean algorithm. J. Atmos. Sci., 55, 1613-1627, doi:10.1175/1520-0469(1998)055<1613:SIRRWA>2.0.CO;2.

— , and T. F. Meissner, 2000: Algorithm Theoretical Basis Document (ATBD): AMSR ocean algorithm, version 2. RSS Tech. Proposal 121599A-1, 59 pp., https://eospso.nasa.gov/ sites/default/files/atbd/atbd-amsr-ocean.pdf.

— (ATBD): AMSR-E ocean algorithms. RSS Tech. Rep. 051707, 6 pp., http://images.remss.com/papers/amsr/AMSR_Ocean_ Algorithm_Version_2_Supplement_1.pdf.

Wilheit, T. T., A. T. C. Chang, M. S. V. Rao, E. B. Rodgers, and J. S. Theon, 1977: A satellite technique for quantitatively mapping rainfall rates over the ocean. J. Appl. Meteor., 16, 551-560, doi:10.1175/1520-0450(1977)016<0551:ASTFQM>2.0.CO;2.

Wood, R., K. K. Comstock, C. S. Bretherton, C. Cornish, J. Tomlinson, D. R. Collins, and C. Fairall, 2008: Open cellular structure in marine stratocumulus sheets. J. Geophys. Res., 113, D12207, doi:10.1029/2007JD009371.

— M. Köhler, R. Bennartz, and C. O'Dell, 2009: The diurnal cycle of surface divergence over the global oceans. Quart. J. Roy. Meteor. Soc., 135, 1484-1493, doi:10.1002/qj.451.

Zelinka, M. D., S. A. Klein, and D. L. Hartmann, 2012a: Computing and partitioning cloud feedbacks using cloud property histograms. Part I: Cloud radiative kernels. J. Climate, 25, 3715-3735, doi:10.1175/JCLI-D-11-00248.1.

, — - and _ 2012b: Computing and partitioning cloud feedbacks using cloud property histograms. Part II: Attribution to changes in cloud amount, altitude, and optical depth. J. Climate, 25, 3736-3754, doi:10.1175/JCLI-D-11-00249.1. 